\title{
INCORPORACIÓN DE LA ÉTICA ANIMAL AL DERECHO
}

\author{
PABLO SERRA PALAO \\ pabloserrapalao@gmail.es
}

\begin{abstract}
RESUMEN: Este trabajo tiene por objeto principal el análisis de la normativa que más afecta a la situación de los animales utilizados por el ser humano, en concreto en el sector de la ganadería industrial. Asimismo, el fundamento filosófico de la ética animal podrá ayudar a llegar a la conclusión de que la evolución hacia una sociedad más justa debe llevar aparejada, necesariamente, la supresión de una serie de prácticas que causan un enorme sufrimiento a los animales. Las medidas proteccionistas de su bienestar son insuficientes para tomar realmente en consideración sus propios intereses, puesto que perpetúan la utilización del resto de animales para nuestro beneficio. De esta manera, se presenta como una posibilidad a largo plazo el reflejo en el derecho de la abolición de todo tipo de explotación animal.
\end{abstract}

PALABRAS CLAVE: derecho animal, ética animal.

ABSTRACT: The main aim of this work is to analyse the legislation that most affects the situation of animals used by humans, particularly in the industrial livestock sector. Furthermore, the philosophical basis of animal ethics may help to conclude that the evolution towards a fairer society must necessarily lead to the elimination of a number of practices that cause enormous suffering to animals. Protectionist measures for their welfare are insufficient to really take their own interests into account, as they perpetuate the use of other animals for our benefit. In this way, the reflection in the law of the abolition of all forms of animal exploitation is presented as a long-term possibility.

KEYWORDS: animal law, animal ethics.

SUMARIO: I. FUNDAMENTO FILOSÓFICO DE LA INCORPORACIÓN DE LA ÉTICA ANIMAL AL DERECHO - I.1 Introducción a la ética animal - I.2 El igualitarismo - I.3 El bienestarismo - I.4 Derechos Humanos y Derechos de los Animales, ¿.es necesaria esa dicotomía? - I.5 Antiespecismo, veganismo y abolicionismo: nuevo paradigma para el Derecho - II. ANÁLISIS DE LA LEGISLACIÓN VIGENTE - II.1 Normativa europea - II.1.1 El bienestar animal en la ganadería industrial II.1.1.1 Cerdos - II.1.1.2 Terneros - II.1.1.3 Gallinas ponedoras y pollos para la producción de carne - II.1.2 El bienestar animal y los animales de compañía - II.2 Normativa estatal - II.2.1 El bienestar animal en la ganadería industrial - II.2.1.1 Cerdos - II.2.1.2 Terneros - II.2.1.3 Gallinas ponedoras y pollos para la producción de carne II.2.1.4 Conejos - II.2.2 El bienestar animal y los animales de compañía - II.2.3 El maltrato animal en el Código Penal - II.3 Normativa autonómica - III. Conclusiones - III.1 Por qué el bienestarismo es insuficiente - III.2 Los tres pilares: Ética, Medio Ambiente y Salud - III.3 Por un futuro sin utilizar animales: el abolicionismo en el Derecho es posible - IV. REFERENCIAS BIBLIOGRÁFICAS.

\section{FUNDAMENTO FILOSÓFICO DE LA INCORPORACIÓN DE LA ÉTICA ANIMAL AL DERECHO}

La intención de esta primera parte consiste, sencillamente, en ofrecer una serie de conceptos básicos que ayuden a modificar el efecto que en cualquier persona podría causar el análisis de la normativa sobre determinadas prácticas relacionadas con los animales, de tal manera que pueda llegar por sí sola a la conclusión de que un cambio en la relación con el resto de animales se ha vuelto urgente y necesario. Entiéndase que en todo el texto será empleado el 
término "animal" para referirse a los "animales no humanos", por razones de lógica expositiva, aunque este último sea más preciso.

\section{I.1 Introducción a la ética animal.}

Pecaría de pretencioso este trabajo si un estudiante del Grado en Derecho tuviera la más mínima intención de abordar el intrincado estudio de la ética animal. No obstante, se ha considerado necesario y, sobre todo, útil, llevar a cabo una modesta introducción a la misma con el ánimo de advertir que la gravedad del asunto es mucho mayor de lo que parece: incide directamente en la propia ética, hasta el punto de que la percepción que tenemos del resto de animales y el trato que les damos nos define como individuos y como sociedad.

Así, se puede decir, de acuerdo con lo expresado por la Fundación Ética Animal, que se está ante el campo de la ética que trata cómo y por qué deberíamos tomar a los animales no humanos en cuenta en nuestras decisiones morales. ${ }^{1}$ Como bien apunta Óscar Horta, el ser humano yerra en la idea de pensar que es especial, lo cual tiene como grave consecuencia el intento de justificación de su conducta hacia el resto de animales. ${ }^{2}$

Tal y como señalan Lauren Steffen y Klanovicz de Araújo, los estudios sobre cómo deberían ser tratados los animales han aumentado considerablemente, consecuencia en gran parte de un despertar de la sociedad acerca de esta problemática. ${ }^{3}$

La ética animal está inundada de teorías, en especial a partir de los años 70, las cuales divergen en muchos aspectos que las definen y caracterizan. Sin embargo, Óscar Horta indica que el denominador común apreciable en todas ellas (utilitarismo, ética de los derechos, contractualismo, enfoques aristotélicos, ética del cuidado, igualitarismo) es el planteamiento o contundente rechazo del antropocentrismo moral (entendiendo por tal los enunciados normativos a los que se refiere cuando se considera o actúa favoreciendo ${ }^{4}$ ), por lo que sería más producente optar por una perspectiva centrada en los argumentos que desde cada teoría se emplean para rechazar el especismo. ${ }^{5}$

El término "especismo" aparece por vez primera en 1970 de la mano de Richard D. Ryder, en un folleto que envió a toda la comunidad universitaria para poner en tela de juicio la discriminación que recibían el resto de animales por el mero hecho de pertenecer a una determinada especie. ${ }^{6}$ En este sentido, Carlos Alberto Crespo Carrillo define el especismo como el prejuicio o actitud parcial favorable a los intereses de los miembros de nuestra propia especie, o de algunas especies, y en contra de los de otras. Así, por lo tanto, Crespo Carrillo

\footnotetext{
${ }^{1}$ Una breve introducción de las distintas teorías éticas se puede encontrar aquí: http://www.animal-ethics.org/eticaanimales-seccion/teorias-eticas-animales-no-humanos/. Fecha de acceso: 20-06-2018.

${ }^{2}$ HORTA, O., Un paso adelante en defensa de los animales, Madrid, Plaza y Valdés Editores, 2017, 20-21.

3 LAUREN STEFFEN, J. y KLANOVICZ DE ARAÚJO, C., "Animal ethics theories: the current debate", $d A$. Derecho Animal: Forum of Animal Law Studies, 2015, Vol. 6, № 3.

${ }^{4}$ LEYTON DONOSO, F., "Bioética frente a los derechos animales: tensión en las fronteras de la filosofía moral", Tesis doctoral dirigida por Óscar Horta Álvarez y Norbert Bilbeny, Universitat de Barcelona, 2015, 134.

${ }^{5}$ HORTA, O., "El cuestionamiento del antropocentrismo: distintos enfoques normativos", Revista de Bioética y Derecho, No $16,2009,36-39$.

${ }^{6}$ RYDER, R. D., “Speciesism Again: the original leaflet”, Critical Society, 2010, 1-2.
} 
entiende que el especismo hace que el animal humano discrimine al resto de animales no humanos, declarándolos de su propiedad y haciéndolos sus esclavos para su propio beneficio. ${ }^{7}$

Otras formas de discriminación por diversos motivos entre seres humanos, tales como el racismo, sexismo o el clasismo, han sido y, lamentablemente, son, defendidas y consideradas legítimas por el grupo de seres humanos que se ve beneficiado por esa discriminación. Así como en el sexismo o clasismo se trata peor a otro ser humano por pertenecer a un sexo o clase social, en el especismo se discrimina por pertenecer a una especie.

Como colofón final a esta introducción, Peter Singer sostiene que no hay una base que pueda justificar dibujar el límite de la consideración moral directa (algo que tiene valor en sí o por sí mismo, por ejemplo, el hecho de vivir o la felicidad) alrededor de nuestra propia especie y no ampliarla al resto de animales no humanos. Por ello, defiende una ética no especista, que se extienda a todos los seres que tengan esa capacidad de tener experiencias, de sentir placer o dolor. Es decir, a todos los seres sintientes. ${ }^{8}$

Para reforzar esta afirmación cobra especial relevancia la Declaración sobre la Consciencia de Cambridge, con fecha de 7 de Julio de 2012, en la que se declaró que muchos animales no humanos eran seres conscientes, lo cual suponía que eran sintientes. Así, se vino a afirmar que "los humanos no somos los únicos en poseer la base neurológica que da lugar a la consciencia. Los animales no humanos, incluyendo a todos los mamíferos y aves, y otras muchas criaturas, entre las que se encuentran los pulpos, también poseen estos sustratos neurológicos". 9

\section{I.2 El igualitarismo}

En el apartado anterior, al referirse a las distintas teorías que rechazan el especismo antropocéntrico, destaca el igualitarismo. Para comprenderla mejor, la filósofa Catia Faria ofrece una definición del igualitarismo, según el cual: "debemos actuar con el fin de aumentar la igualdad entre los individuos que puedan ser afectados por nuestra acción o debemos actuar con el fin de reducir la desigualdad entre los individuos que puedan ser afectados por nuestra acción." Ligando el igualitarismo con el prioritarismo (asignar mayores beneficios a los individuos que estén en peor situación), Catia Faria adopta la "tesis igualitarista amplia", entendiéndola como la distribución más igual de recursos entre individuos de tal forma que quienes están peor se vean afectados para mejor. ${ }^{10}$

Muchos animales no humanos, entrando en tema, son seres sintientes capaces de vivenciar experiencias positivas y negativas. Esto hace que posean un bienestar propio, por lo que les será perfectamente aplicable la tesis igualitarista, tal y como afirma Catia Faria. De esto extrae que el bienestar humano y el no humano deben ser igualmente considerados, llevando a

\footnotetext{
7 CRESPO CARRILlO, C. A., "Liberación animal desde una bioética no especista", A.G.I.D., La cuestión animal(ista), Bogotá, Ediciones desde abajo, 2016, 359-368.

${ }^{8}$ SINGER, P., “Ética más allá de los límites de la especie”, Teorema: Revista internacional de filosofía, 1999, № 3, 5-16.

${ }^{9}$ Esta Declaración fue redactada por Philip Low y revisada por Jaak Panksepp, Diana Reiss, David Edelman, Bruno Van Swinderen, Philip Low y Christof Koch. El texto, en inglés, puede leerse aquí: http://fcmconference.org/img/CambridgeDeclarationOnConsciousness.pdf

${ }^{10}$ FARIA, C., "Equality, Priority and Nonhuman Animals", No 14, Dilemata, 2014, 225-236.
} 
cabo la distribución del bienestar más igual entre individuos, independientemente de su especie. $^{11}$

Finalmente, también Óscar Horta expone que desde el igualitarismo se puede defender perfectamente la posición de considerar los intereses de los animales no humanos, puesto que se debe intentar mejorar la situación de quienes se encuentran peor, independientemente del potencial que un individuo tiene para el disfrute de un valor (por ejemplo, poseer toda una serie de capacidades cognitivas frente a quien carece de estas). ${ }^{12}$

\section{I.3 El bienestarismo}

Toda la normativa vigente en la actualidad y los avances por medio de las sucesivas reformas en cuanto al trato de los animales no logran (más bien, no quieren) salir de esta corriente de la ética animal. Advertido esto, y en palabras de la filósofa Corine Pelluchon, "el bienestarismo se limita a preconizar la mejora de las condiciones de vida de los animales, su bienestar, y no la supresión de la explotación animal." "13

Por lo tanto, evidentemente se reconoce que los animales son seres sintientes, o que se tiene interés en evitar una crueldad, dolor, padecimiento o sufrimiento innecesarios. De hecho, muchas de las leyes que serán expuestas en la siguiente parte reproducen ambas premisas, pero lejos de que esto conduzca a la erradicación progresiva de su utilización por los humanos, lo que favorece es perpetuar un sistema de producción, en el que la reducción del sufrimiento o aumentar los niveles de felicidad de un animal durante su corta vida en una granja industrial son aplaudidas (por los seres humanos, claro está) como auténticas victorias.

En este sentido, Ana María Aboglio denuncia que el único objetivo de las leyes de protección animal (de las cuales se van a ver unas cuantas) es condenar el trato inhumano y la crueldad patológica, aplicándose, claro está, en un marco donde se sobrentiende que a los otros animales se les puede utilizar con determinados fines. ${ }^{14}$ Así, su condición de ser-producto sometido a la voluntad del ser humano se prolonga indefinidamente.

Otro de los objetivos, perversos, de la normativa sobre bienestar animal (o la regulación de la crueldad), es tratar de disipar a tiempo cualquier sospecha de que se esté generando en el ser humano un debate moral interno sobre todo lo que hay detrás de ese plato de carne. El bombardeo constante de que los animales no sufren, que se garantiza su bienestar animal o que los productos animales son necesarios, consiguen, de momento, evitar la conexión a tiempo entre el animal humano y no humano, de tal forma que el primero vea al segundo, no como a un ser con la capacidad de tener experiencias positivas y negativas, de vivir, disfrutar o sufrir, sino como a un producto final.

Incluso, se podrá apreciar posteriormente el marcado carácter antropocentrista de las leyes, en las que el interés hacia los animales esclavizados es puramente indirecto. A pesar de

\footnotetext{
${ }^{11}$ FARIA, C., "Equality, Priority and Nonhuman Animals".

${ }^{12}$ HORTA, O., "Igualitarismo, igualación a la baja, antropocentrismo y valor de la vida, Revista de Filosofía, 2010, $\mathrm{N}^{\circ}$ 1, 133-152.

${ }^{13}$ PELlUCHON, C., Manifiesto animalista, Barcelona, Penguin Random House Grupo Editorial, 2018, 129 (título original: Manifeste animaliste, París, Alma Éditeur, 2017).

${ }^{14}$ ABOGLIO, A. M., "Discurso proteccionista y opresión animal”, A.G.I.D., La cuestión animal(ista), 111-148.
} 
que este interés indirecto suponga un fin en sí mismo, se dirige a lo que realmente importa o se pretende, esto es, el interés directo. Por lo tanto, la preocupación de los animales se debe, prácticamente, a razones de conveniencia. En este sentido, el interés directo reside en el propio ser humano, en su salud, en la productividad económica de las empresas y en la próspera evolución del sector, siendo una idea fuerza en estos textos el hecho de que el bienestar animal incide en la calidad final del producto.

Sentado todo lo anterior, se ha considerado necesario, por el contexto de este trabajo, que los comentarios de la normativa contenida en el mismo se hayan realizado de la forma más objetiva posible, incluso es admisible decir que su análisis se ha llevado a cabo bajo la óptica del bienestarismo, enfatizando aquellos supuestos en los que las condiciones de vida no llegan ni a los mínimos del bienestar animal establecidos por la propia normativa.

\section{I.4 Derechos Humanos y Derechos de los Animales, ¿es necesaria esa dicotomía?}

La categoría de derechos humanos, entendida como fundamentales o esenciales al desarrollo de todo individuo, se encarga de proteger una serie de intereses especialmente valiosos para la propia existencia. Así, son derechos que tienen todos los seres humanos por el mero hecho de serlo, por lo que su respeto se vuelve vital para crear un entorno de libertad y justicia. Sin embargo, la intención aquí no es su estudio, ni mucho menos, sino la relación entre estos y los derechos de los animales, así como la posibilidad de suprimir esa distinción entre ambas categorías. Para poder responder a la necesidad o no de esta dualidad de derechos, humanos y animales, habría que preguntarse primero qué es lo que se necesita para tener un derecho.

Haciéndose eco de ella, David Gallego Amores expresa que un derecho es inherente a un individuo cualquiera que sea la circunstancia moral en la que se encuentre, al representar un interés que aparece como inherente a su propia condición de ser sintiente. ${ }^{15}$ Por lo tanto, todo ser sintiente tiene derechos. Esto mismo es defendido por María José Guerra Palmero, quien manifiesta la desconfianza en el propio ser humano para la asunción de responsabilidades morales, por lo que acudir a los derechos como un indicador de garantías se vuelve imperativo, convirtiéndose en un progreso moral y legal que obliga a ser responsables para con los seres sintientes. ${ }^{16}$

Por otra parte, resulta de especial interés en este tema abordar el análisis que hace Mikel Torres Aldave sobre la teoría de los derechos de los animales de Tom Regan. ${ }^{17}$ De acuerdo con el análisis de Mikel Torres, esta teoría habla de derechos morales, cuya titularidad prohíbe al resto ser moralmente libre de hacer daño y de interferir en las libres elecciones del individuo que los ostenta. Asimismo, generan deberes correlativos al resto de individuos, esto significa, por ejemplo, que el derecho a la vida generaría en el resto de individuos el deber de proteger ese derecho. Para esta teoría, los criterios fundamentales que determinan qué seres son poseedores de estos derechos morales y cuáles no, son ser "sujetos de una vida" y el "valor inherente". En cuanto al primero, para tener esta consideración resulta esencial la consciencia, es decir, percibir el mundo, reconocerse en él y tener la capacidad de experimentar, ya sea de forma positiva o

\footnotetext{
${ }^{15}$ GALLEGO AMORES, D., "El reconocimiento de derechos para los animales no humanos como requisito de una sociedad justa", El mejoramiento humano: avances, investigaciones y reflexiones éticas y políticas, Granada, Editorial Comares, 2015, 778-787.

${ }^{16}$ GUERRA PALMERO, M. J., "Derechos de los animales y justicia interespecífica”, Laguna, 2000, 375-379.

${ }^{17}$ TORRES ALDAVE, M., "La teoría de los derechos de los animales de Tom Regan”, biTARTE, 2009, 5-24.
} 
negativa. Por otro lado, todo sujeto de una vida ostenta un valor inherente, entendiendo por tal un valor más allá de lo útil que sea para el resto de los seres.

No obstante lo dispuesto en el párrafo anterior, Mikel Torres viene a defender la teoría de los derechos de los animales no humanos de Martha C. Nussbaum como superior a la de Regan. Como bien reflexiona Mikel Torres, la teoría del "enfoque de las capacidades", denominada así por Nussbaum, incluye la idea de la justicia hacia los animales no humanos, entrando de esta manera en territorio de los derechos fundamentales. Nussbaum, apunta Mikel Torres, respalda que limitar los deberes hacia los animales únicamente a deberes de compasión impediría poder reflexionar adecuadamente sobre nuestros deberes hacia los mismos. Uno de los puntos por los cuales da preferencia a esta teoría frente a la de Regan, es el origen de los principios morales y políticos, al ofrecer Nussbaum la posibilidad de que las propias personas que elaboran los principios incluyan a seres no humanos como sujetos de pleno derecho de estos principios. ${ }^{18}$

Tras todo lo dicho anteriormente, es perfectamente plausible llegar a la conclusión de que la dualidad existente puede ser olvidada con respecto a determinados derechos o principios fundamentales, reforzando por tanto la idea de que los animales no humanos pueden ser sujetos de pleno derecho de los mismos, por lo que sería perfectamente válido hablar de unos derechos fundamentales de todos los seres sintientes, humanos y no humanos.

\section{I.5 Antiespecismo, veganismo y abolicionismo: nuevo paradigma para el Derecho}

Estos tres términos, íntimamente conectados entre sí, sin duda alguna están dando y van a dar mucho de qué hablar en la esfera política, no tanto en el ámbito jurídico que, como es apreciable, inevitablemente se halla varios pasos por detrás de los cambios sociales. La idea de este apartado no es, en absoluto, ahondar en cada uno de los postulados del título, sino tener bien presente que más pronto que tarde estas premisas van a ser trasladadas a la política. De hecho, Corine Pelluchon insiste en que la supresión a corto plazo de una serie de prácticas que causan un enorme sufrimiento a los animales, puede contar con la aprobación de la mayoría de los ciudadanos. Adicionalmente, ve obvio que la prohibición de estas actividades deba incorporar un plan que contemple el reciclaje de todos los individuos implicados, otorgando ventajas económicas y ayudas que faciliten dicho reciclaje y, lo más importante, que se experimente como una oportunidad de crear un mundo más justo y evolucionar como seres humanos. ${ }^{19}$

Toda persona que lea estas páginas estará ya familiarizada con el término especismo, por lo que conviene empezar por el término antiespecismo. Numerosas escritoras y escritores se han hecho eco de esta nueva consideración moral. Por ejemplo, Michela Pettorali estima que la perspectiva antiespecista considera que dar prioridad a los intereses humanos sobre los demás animales cuando no resultan más importantes es completamente injustificado, convirtiéndose en injustificado el menosprecio y explotación de los segundos para la satisfacción de los intereses humanos. ${ }^{20} \mathrm{El}$ antiespecismo, entonces, se erige como una consideración centrada en la oposición a todo tipo de práctica especista.

\footnotetext{
18 TORRES ALDAVE, M., "Capacidades y derechos de los animales: argumentos a favor de la teoría de M.C. Nussbaum", Dilemata, No 1, 2009, 33-47.

${ }^{19}$ PELLUCHON, C., Manifiesto animalista, 91-92.

${ }^{20}$ PETTORALI, M., "Una crítica a la profesión veterinaria desde una perspectiva antiespecista", Revista de bioética y derecho, $\mathrm{N}^{\circ} 37,2016,121-131$.
} 
Igualmente, el abolicionismo aparece tradicionalmente unido a la supresión de la esclavitud. De esta forma, aplicado al derecho de los animales, consistiría en la eliminación total de cualquier tipo de explotación animal, de tal forma de dejar de utilizarlos como medios para la satisfacción de los fines humanos, erradicando la relación de dominio existente. Nótese que esta postura aparece como la gran abanderada para acabar de forma práctica con un sistema éticamente insostenible, oponiéndose al ya explicado bienestarismo, que únicamente se preocuparía por reducir el sufrimiento y aumentar la felicidad de los animales.

Finalmente, pero no menos importante, queda el veganismo. Una palabra que hoy por hoy es imposible no haberla escuchado, pero que tiene un significado no muy claro dependiendo de quién la esté empleando. Para que se pueda entender fácilmente y evitar de tal forma complicaciones terminológicas que no llevan a ningún lado, lo más útil ha sido acudir directamente a la Vegan Society, fundada en 1944, para traer la definición de veganismo entendido como "una filosofía y forma de vida que busca evitar, en la medida de lo posible y practicable, toda forma de explotación de, y crueldad hacia, los animales, ya sea con el fin de obtener comida, ropa o cualquier otro propósito, y por extensión, el veganismo promueve el desarrollo y uso de alternativas libres de uso de animales para el beneficio de los humanos, animales y el medio ambiente. En términos alimenticios, supone prescindir de todos los productos derivados total o parcialmente de los animales. ${ }^{21}$ Personalmente, no veo una mejor manera de describir este término.

\section{ANÁLISIS DE LA LEGISLACIÓN VIGENTE}

La legislación referida a los animales es tan amplia que abarca numerosos campos de actuación, los cuales van desde la normativa específica en el ámbito de sanidad alimentaria hasta lo más llamativo y en donde se va a reparar a lo largo de toda esta parte: el bienestar animal en la ganadería industrial. Por esta razón, se ha reducido la exposición y análisis a aquellos textos normativos que se han considerado más útiles (pero no más importantes), con la finalidad de tener una visión de lo que implica la utilización de los animales para nuestro propio interés. Así, tanto la normativa europea como estatal se estudiará en base a dos apartados: bienestar animal en la ganadería industrial y bienestar animal en lo referente a los animales de compañía, distinción esta que, tal y como se ha podido observar a raíz de la primera parte de este trabajo, es una pura consecuencia del especismo.

Esta introducción a la presente parte no puede obviar hacer referencia a la Organización

\footnotetext{
${ }^{21}$ La definición se encuentra en la página web de la Vegan Society: https://www.vegansociety.com/govegan/definition-veganism
} 
Por otro lado, la noción de posicionar el bienestar del ser humano como fin del bienestar animal se sigue en las recomendaciones de la Autoridad Europea de Seguridad Alimentaria (EFSA, por sus siglas en inglés). De hecho, la preocupación recae en el propio consumidor, indicando que "la seguridad de la cadena alimentaria está afectada de forma indirecta por el bienestar de los animales, lo cual puede conllevar riesgos al consumidor." No obstante, esto no es ninguna sorpresa, puesto que la propia Autoridad Europea señala que no tiene un mandato para dar consejos sobre cuestiones éticas o culturales relacionadas con el bienestar animal.

Por lo tanto, si se es consciente de lo expuesto hasta ahora, resultará fácilmente comprobable que el interés en el propio bienestar de los animales, lo cual no quiere decir otra cosa más que el estado en el que se encuentran, es un interés indirecto, constituyendo por su parte el interés principal el del consumidor de productos provenientes de animales. La normativa desarrollada a continuación, en lo que respecta a los animales no considerados de compañía, es fiel a esta orientación.

\section{II.1 Normativa europea}

Protección de los animales en las explotaciones ganaderas, en el traslado y en el momento de su sacrificio. La normativa europea en lo que concierne al bienestar animal gira en torno a estos tres ejes principales, pero también cobra especial importancia el estado en el que se encuentran los animales utilizados con fines experimentales u otros fines científicos.

Aun sabiendo que los cambios sociales se reflejan tardíamente en nuestra legislación, y que la preocupación por los animales ha sido minoritaria hasta hace poco tiempo, se puede decir que el avance que se ha dado en la normativa a nivel europeo en relación a los animales es destacable.

Ya en 1968, el Consejo de Europa dictó el Convenio Europeo para la protección de los Animales en el Transporte Internacional. Esta versión, la cual no fue firmada ni ratificada por la Unión Europea, sufrió una revisión en 2003. Esta última (ya ratificada por la Unión Europea aunque no por España, que sí ratificó el texto de 1968) incorpora, con anterioridad al articulado y a diferencia de lo que ocurre en el texto original, que las personas tienen una obligación moral de respetar a todos los animales. Se advierte, realizando un análisis comparado de ambas versiones, que en la versión actual existe una preocupación mucho mayor en lo que atañe al estado de los animales.

El Convenio, que abarca el transporte de todo animal vertebrado, no resulta de aplicación en dos casos: en primer lugar, cuando un único animal es acompañado por la persona responsable durante el transporte; y en segundo lugar, en el transporte de animales de compañía acompañados de su dueño, siempre que no sea con un propósito comercial (art. 2). Esa preocupación mayor que supuso la revisión del texto en 2003 se ve reflejada a lo largo de todo el Convenio. Ejemplo claro de ello lo vemos en relación con el embarazo de los mamíferos. En 1968 se preveía, en su art. 4, que aquellos animales que habían dado a luz en las anteriores 48 horas no debían ser considerados aptos para el transporte. Esta situación mejoró notablemente a partir de 2003, puesto que ahora se prohíbe el transporte de mamíferos que se encuentren dentro del 10\% del periodo de gestación anterior a dar a luz, o que hayan dado a luz con -menos de una semana de antelación a la fecha prevista para el transporte (art. 9.3).

Asimismo, la inclusión del art. 5, relativo a la autorización de los transportistas de animales con fines comerciales es otro de los aspectos a remarcar de la revisión del Convenio. En dicho artículo se menciona que estos transportistas deberán estar registrados de forma tal que 
las autoridades competentes de los Estados partes puedan identificarlos en caso de incumplimiento de los requisitos del Convenio. Además, la autorización habrá de ser válida para el transporte internacional, emitida por la autoridad competente del Estado parte en el que el transportista esté radicado.

Siguiendo una línea cronológica, nos encontramos que ya en 1974 el Consejo de las Comunidades Europeas dictó la Directiva 74/577/CEE, relativa al aturdimiento de los animales antes de su sacrificio. Esta Directiva, que sería derogada por otra de 1993 y ésta a su vez por el Reglamento (CE) 1099/2009 del Consejo (el cual se explicará con detalle en el apartado siguiente), supuso la aplicación en los Estados miembros del aturdimiento de los animales mediante diversos métodos, de forma tal que se encuentren en un estado de inconsciencia al llegar el momento de su muerte. No obstante, esta buena voluntad de evitar un sufrimiento innecesario al animal se ve opacada por el recelo del Consejo en que los métodos utilizados no tengan repercusión en la "salubridad de la carne". He aquí un caso más de que el estado del animal sigue siendo secundario para la legislación.

El 10 de marzo de 1976 es una fecha que sin duda marcó un antes y un después en el estado de los animales. Ese día veía la luz, de la mano del Consejo de Europa, el Convenio Europeo sobre la protección de los animales en las ganaderías. En él se establecieron los principios básicos de protección de los animales que se encontraban en explotaciones ganaderas (arts. 3 a 7 del Convenio):

- Alojamiento, alimentación y cuidados apropiados para sus necesidades fisiológicas y etiológicas (art. 3).

- Libertad de movimiento del animal, sin ser obstaculizada de forma tal que se le causen sufrimientos inútiles (art. 4).

- Las condiciones del ambiente, tales como la iluminación, la temperatura o la intensidad del ruido, deberán ser apropiadas a las necesidades del animal (art. 5).

- Los animales no podrán ser alimentados de tal forma que de ello se derive cualquier sufrimiento inútil (art. 6).

- Inspecciones, por lo menos una vez al día, de las condiciones y estado de salud de los animales, así como de las instalaciones (art. 7).

Este Convenio también dispuso la creación de un Comité Permanente, conformado por un representante de cada parte contratante. Dicho Comité se encargaría de elaborar recomendaciones a las partes contratantes para la aplicación de los principios enumerados, las cuales fueron adoptadas a partir de 1986, siendo la última de 2005, relativa a los peces de piscifactoría.

Cercanos a la fecha en que se dictó este Convenio, el Farm Animal Welfare Council (que a partir de 2011 pasó a denominarse Farm Animal Welfare Committee), organismo público no dependiente de ningún Ministerio del Reino Unido, adoptó lo que sería la base para numerosa legislación posterior: "las cinco libertades". La libertad de hambre y sed, de incomodidad, la libertad de dolor, heridas o enfermedades, de expresar un comportamiento normal, así como la libertad de miedo y estrés, pretendían constituir un marco mucho más ambicioso que mejorara la situación de los animales retenidos por el ser humano en explotaciones ganaderas. 
Habiendo tomado la iniciativa el Consejo de las Comunidades Europeas en lo referente a tratar el momento del sacrificio de los animales (aunque con una Directiva, ya mencionada, bastante deficiente y laxa en el tema), el Consejo de Europa quiso estar a la altura, firmando el 10 de mayo de 1979 el Convenio Europeo para la Protección de los Animales al Sacrificio (texto que, lamentablemente, no fue firmado ni ratificado por España). A lo largo del texto se puede ver el intento de que, incluso en el matadero, queden reflejadas esas cinco libertades mencionadas en el párrafo anterior. Intento porque resulta obvio, y numerosos testimonios de trabajadores en mataderos así lo demuestran, que el propio animal es capaz de oír los gritos, oler la sangre y ser consciente de hacia dónde lo están dirigiendo. ${ }^{22}$

El interés por evitar que el animal sufra innecesariamente en los distintos estadios del proceso, desde que llega al matadero hasta su sacrificio, se ve reflejado en los artículos relacionados con el movimiento de los animales dentro del recinto (arts. 4-6) o en el art. 7, que versa sobre la estabulación (mantenimiento de los animales en establos o zonas cubiertas) en el matadero. Por lo que respecta a los primeros, refuerzan la idea de que todas las instalaciones deben ser adecuadas para los animales. De esta forma, alguna de las indicaciones es evitar utilizar un material resbaladizo para el suelo o con la mínima inclinación posible. Además, prohíbe el empleo de golpes o patadas así como retorcer las colas para obligar a que los animales se muevan. Finalmente, el art. 6 introduce el contenido del art.7, al indicar que en caso de que los animales no sean sacrificados inmediatamente, deberán estabularse. De esta manera, dicho artículo ofrece todas las instrucciones referidas a la estabulación, tales como la protección de condiciones climáticas adversas, áreas con suficientes bebederos y comederos o, si es necesario atarlos, que sea de tal forma que permita al animal recostarse.

A pesar de que se haya decidido no desarrollar posteriormente de manera exhaustiva el bienestar de los animales utilizados para la experimentación, evidentemente se merece una breve mención el Convenio Europeo sobre protección de los animales vertebrados utilizados con fines experimentales y otros fines científicos, de 18 de marzo de 1986. Merece en primer lugar resaltar la contradicción contenida en su Preámbulo, puesto que, al mismo tiempo que reconoce la obligación de las personas de respetar a los animales y tener en cuenta su capacidad de sufrimiento, seguidamente justifica su utilización para la búsqueda del conocimiento o la salud. Sin embargo, lo que más llama la atención es que equipara la razón de utilizarlos para estos fines con la de usarlos para alimento o vestido, como si estos dos últimos estuvieran realmente justificados para el progreso del ser humano (lo cual no quiere decir que la primera esté justificada). Por otro lado, desde una perspectiva optimista, es preciso destacar su art. 6, de cuyo contenido se desprende evitar, en la medida de lo posible, la utilización de animales para los fines previstos en el art. 2 (procedimientos para la prevención de enfermedades, protección del medio ambiente, investigación científica, etc.) cuando pueda recurrirse a un método alternativo que alcance los mismos resultados.

Avanzando en el tiempo, y ya dentro de la legislación propia de la Unión Europea, las diversas propuestas de varios Estados miembros sobre incluir textos de bienestar animal en el Tratado de Ámsterdam (1997) finalmente tomaron la forma de protocolo, incorporándose al texto del Tratado el Protocolo sobre la protección y el bienestar de los animales. En él, además de considerar a los animales como "seres sensibles", los Estados miembros acuerdan insertar como anexo al Tratado Constitutivo de la Comunidad Europea, el siguiente párrafo:

\footnotetext{
${ }^{22}$ Un extenso recopilatorio sobre testimonios de lo que ocurre puertas para adentro en la industria de la carne de Estados Unidos se puede encontrar en el estremecedor libro de Gail A. Eisnitz: Slaughterhouse, New York, Prometheus Books, 1997.
} 
"Al formular y aplicar las políticas comunitarias en materia de agricultura, transporte, mercado interior e investigación, la Comunidad y los Estados miembros tendrán plenamente en cuenta las exigencias en materia de bienestar de los animales, respetando al mismo tiempo las disposiciones legales o administrativas y las costumbres de los Estados miembros relativas, en particular, a ritos religiosos, tradiciones culturales y patrimonio regional."

Resulta evidente que la excepción contenida en la última parte del párrafo se encuentra intrínsecamente ligada a la voluntad de evitar conflictos con los distintos Estados miembros y sus fiestas tradicionales, como es el caso de España y las corridas de toros, sobre todo por cuestiones de materia competencial.

Ya en 2006, la Comisión Europea presenta el 23 de enero un plan de acción comunitario sobre protección y bienestar de los animales 2006-2010. Enlazando con lo visto anteriormente, la Comisión sostenía en la introducción de este plan que respondía a los principios establecidos en el Protocolo sobre la protección y el bienestar de los animales mencionado. En el periodo definido, se establecieron cinco objetivos, así como cinco ámbitos de acción principales para alcanzarlos. El enfoque demasiado general de los objetivos (entre los cuales se encuentran la promoción de unos elevados niveles de bienestar animal en la Unión Europea y a nivel internacional) se ve compensado por las actuaciones concretas, dentro de la línea de los ámbitos de acción, que pretende realizar la Comisión. De este modo, tres páginas de labores concretas (presentación de un informe el Consejo y al Parlamento Europeo sobre la protección de los cerdos destinados a la cría, entre muchas otras) completan este conjunto de trabajos referidos al bienestar animal para el periodo antedicho.

Volviendo a la importancia de los Tratados en el ámbito europeo, con la firma en 2007 del Tratado de Lisboa se incorporó el texto del art. 13 al Tratado de Funcionamiento de la Unión Europea. El contenido del mismo es una copia casi literal del Protocolo que en su momento se anexó al Tratado constitutivo de la Comunidad Europea. Se realizan unos cambios menores, como añadir la política de pesca, desarrollo tecnológico y espacio, si bien existe un detalle (considero) muy importante de referirse a los animales como seres sensibles.

Por otra parte, y retomando el tema de la utilización de los animales con fines experimentales, también es necesario, a pesar de que no sea expuesto con toda su complejidad, apuntar la repercusión que tuvo el Reglamento 1223/2009, del Parlamento Europeo y del Consejo, de 30 de noviembre de 2009, sobre los productos cosméticos. Es importante subrayar que este Reglamento parte de la prohibición, desde el 11 de marzo de 2009, de comercializar productos cosméticos cuya formulación final, ingredientes o combinaciones de ingredientes hayan sido experimentados en animales. A pesar de ello, continúa diciendo que en determinados casos, como por ejemplo experimentos en materia de toxicidad para la función reproductora, se amplía este plazo al 11 de marzo de 2013. Esto se sustenta en que "es posible garantizar la seguridad de los ingredientes empleados en los productos cosméticos usando métodos alternativos que no impliquen la utilización de animales y que estén validados u homologados por el Centro Europeo para la Validación de Métodos Alternativos (CEVMA), con la consideración previa de la Organización de Cooperación y Desarrollo Económicos (OCDE)." No obstante, parece difícil que una victoria por los animales sea completa, puesto que su art. 18 contempla (cómo no) la posibilidad de solicitar una excepción a la Comisión, concediéndose si el uso del ingrediente experimentado en animales no puede sustituirse por otro que desempeñe una función similar. Así las cosas, la concesión de excepciones así como el hecho de que ingredientes empleados en productos de limpieza o farmacéuticos (donde no existe esta prohibición de experimentar con animales) sean también usados en productos cosméticos dejan un sabor amargo a lo que, prima facie, era un gran avance en la defensa de los animales. 
Si en 2006 la Comisión lanzaba su plan de acción comunitario sobre protección y bienestar de los animales 2006-2010, a comienzos de 2012 comunicó al Parlamento Europeo, al Consejo y al Comité Económico y Social Europeo la estrategia de la Unión Europea para la protección y el bienestar de los animales 2012-2015. Sustituyendo al plan anterior y basándose en la experiencia adquirida, esta estrategia centra su atención en una serie de factores que afectan al bienestar animal en la Unión.

Entre dichos factores, lo más preocupante radica en la falta de aplicación de la legislación de la UE por parte de los Estados miembros. De esta manera, se reconoce en el propio texto que muchos de los países no adoptan las medidas necesarias para garantizar que los mínimos de respeto hacia los animales dentro del sistema productivo se estén cumpliendo, convirtiéndose la normativa europea en una mera declaración de buenas intenciones.

Grandes cantidades de animales sacrificados sin aturdimiento, hacinamiento en granjas, falta de luz y movilidad, malos tratos por parte de los trabajadores ${ }^{23}$, estrés, enfermedades o condiciones deplorables en el transporte constituyen el día a día para millones de animales a lo largo de toda la Unión Europea. Es por esto que la Comisión propone, entre otras cosas, establecer un marco jurídico simplificado en esta materia que facilite su aplicación, planteando el uso de indicadores de bienestar animal con base científica, así como prestando especial atención a la mejora de la transparencia en la información sobre el bienestar animal destinada a los consumidores para que influya de forma más decisiva a la hora de comprar sobre aquellos productos que cumplen con la normativa.

La mejor manera de dar paso a la exposición detallada del bienestar animal en la ganadería industrial, es comentar la petición que hizo el Parlamento Europeo y el Consejo, en 2015 y 2016 respectivamente, de crear una Plataforma de bienestar animal, con el ánimo de favorecer el diálogo entre todas las partes interesadas en el asunto.

Finalmente, mediante decisión de la Comisión de 24 de enero de 2017, se crea un grupo de expertos denominado "Plataforma de bienestar animal", con el ánimo de asistir a la Comisión en todos los aspectos relacionados con la temática.

Formada por representantes de las autoridades de los Estados miembros con competencias en bienestar animal, de las empresas implicadas en la cadena alimentaria de origen animal a nivel europeo, así como en la cría de animales, de organizaciones dedicadas al bienestar animal con impacto en la Unión Europea, así como de centros académicos y científicos dedicados a esta cuestión (art. 4), sus principales funciones son las siguientes (art. 2):

- Contribuir a la puesta en práctica y aplicación de la legislación europea sobre bienestar animal, así como a la comprensión de la misma.

- Promover dichas normas para aumentar el valor de mercado de los productos europeos.

- Facilitar el desarrollo de compromisos voluntarios para que las empresas mejoren en esta materia.

- Fomentar el diálogo entre los miembros de la Plataforma, contribuyendo el intercambio de experiencias y buenas prácticas.

\footnotetext{
${ }^{23}$ Ejemplo de ello lo encontramos en numerosas investigaciones encubiertas, como se puede observar en el siguiente enlace: http://www.igualdadanimal.org/noticias/6348/igualdad-animal-revela-sadismo-y-brutalidad-ocultos-en-lagranja-de-cerdos-de-el-escobar. Fecha de acceso: 12-07-2018.
} 
Por último, resta por señalar que esta Decisión de la Comisión tendrá aplicabilidad hasta el 31 de diciembre de 2019.

\section{II.1.1 El bienestar animal en la ganadería industrial}

Muchas de las normas que a continuación van a ser descritas es muy probable que ya hayan sido citadas previamente. Sin embargo, debido a que el sector de la ganadería industrial es el principal responsable de las mayores violaciones a los mínimos de bienestar animal establecidos por la legislación, merecen un análisis más extenso.

Pero antes, un paréntesis. Las cifras de animales sacrificados por el ser humano para nuestro consumo son estremecedoras. De acuerdo con Eurostat (la oficina de estadística de la Comisión Europea, encargada de elaborar y publicar estadísticas de la Unión Europea), en la Unión Europea se sacrificaron en el año 2017 casi 26 millones y medio de animales destinados a carne bovina (machos y hembras, así como las vacas lecheras cuando dejan de ser "productivas" para la industria láctea) y alrededor de 255 millones de cerdos. En cuanto a la cantidad de pollos sacrificados, ese mismo año solo en Polonia se alcanzaban los mil millones, por lo que las cifras totales de toda la Unión Europea ni siquiera han sido calculadas por Eurostat (se estima que podría llegar a superar los 7 mil millones, sin contar los patos, pavos, gansos y otras aves que también se sacrifican a diario alrededor de los países miembros). ${ }^{24}$

Dejando de lado las estadísticas, y siguiendo con las normas de bienestar animal bajo el punto de mira, toca volver a hablar del Convenio Europeo sobre protección de los animales en las ganaderías (Consejo de Europa, 1976), pero esta vez junto a las Recomendaciones emitidas por el Comité Permanente del Convenio. Por lo que respecta al Convenio, aparte de los principios básicos de protección de los animales que se encuentran en explotaciones ganaderas contenidos en los artículos 3 a 7 del Convenio, también son relevantes los artículos 8 y 13. Del primero se desprende que el Comité Permanente toma sus decisiones por mayoría de votos, excepto para adopción de Recomendaciones dirigidas a la aplicación de los principios mencionados, para las cuales será necesaria la unanimidad. Del segundo, la obligación del Comité de emitir un informe cada tres años, relativo a su labor y el funcionamiento del Convenio.

Por lo que hace a estas Recomendaciones, se nombró previamente que la primera de ellas tuvo lugar en 1986, en relación con los cerdos. Sustituida por otra de 2004, abarca desde la inspección de las instalaciones, los cerdos y los equipos, pasando por la prohibición general de mutilación hasta la matanza de emergencia. Llama la atención las condiciones deplorables que describe la Recomendación en uno de sus anexos, en concreto el tercero. En él, se recogen las disposiciones relacionadas con las condiciones de las cerdas durante el periodo perinatal, así como de éstas y sus crías durante el periodo de lactancia.

Con anterioridad, es necesario ver cómo es su situación antes de llegar a los compartimentos individuales de parto. La cerda pasa de un periodo de hasta cuatro semanas en una celda individual después de la cubrición o inseminación a un patio con el resto de cerdas gestantes, cuyos grupos pueden variar enormemente en tamaño (durante este periodo se producen agresiones entre ellas, debido a la competencia que se da, por ejemplo, para conseguir la comida o los sitios donde dormir). Así, una vez llegan a la semana antes del parto, son

\footnotetext{
${ }^{24}$ Estos datos, de compleja accesibilidad para la ciudadanía, pueden obtenerse accediendo a la página web de Eurostat: http://ec.europa.eu/eurostat/web/agriculture/data/database
} 
nuevamente trasladadas a compartimentos individuales. En ellas, cuyo espacio es reducido, y en donde normalmente se mantienen rodeadas de sus heces por la falta de limpieza, nacen sus crías. La falta de espacio y movilidad lleva consigo la horrible consecuencia de que alguna de las crías pueda llegar a morir aplastada por la propia madre. Una vez transcurren 28 días desde el parto, las crías son separadas de sus madres para ser llevadas a otra área con el resto de crías. No obstante, las crías pueden llegar a ser destetadas hasta 7 días antes si se cuenta con instalaciones especializadas, debidamente limpias y desinfectadas, según la Recomendación.

Tras esta primera descripción gráfica de las condiciones de un animal dentro de la ganadería industrial, llega el momento de advertir al lector. Esta advertencia radica en que el análisis de la legislación vista hasta ahora así como la que va a ser tratada a continuación se ha realizado con unos altos niveles de objetividad. La situación descrita en el párrafo anterior es lo más fiel posible a la Recomendación emitida por el Consejo de Europa, y con la misma objetividad se seguirá a lo largo de toda esta segunda parte. Asimismo, también es necesario recordar que la realidad en la que viven los animales, víctimas de la ganadería industrial es infinitamente peor que lo que pueda llegar a ser retratado en estas líneas.

El resto de Recomendaciones del Comité Permanente en relación con las distintas especies de animales explotadas para el consumo humano siguen la misma línea de la que se ha hecho mención, con detalles tan característicos como el contenido del art. 9 de la Recomendación concerniente al ganado bovino de 1988, cuyo texto literal es el siguiente: "los animales deberian ser mantenidos en una condición limpia." Esto llama la atención puesto que el texto original en inglés en esta ocasión emplea el verbo modal "should" (que suele utilizarse para expresar un deseo) en lugar de "shall" (que es más común en los textos normativos en inglés emplearlo para obligaciones o deberes), que se utiliza en la mayor parte del resto de artículos. Como si la limpieza del animal, algo tan esencial para su estado, no formara parte de esos mínimos de cuidado.

Otro de los Convenios del Consejo de Europa que ya han sido apuntados es el Convenio Europeo para la protección de los animales durante el transporte internacional, revisado en 2003. En este tema, el Comité de Ministros del Consejo de Europa también emitió Recomendaciones relativas al transporte de las diferentes especies. Sin caer en la reiteración, lo que se puede recalcar ahora es, por ejemplo, su art. 6, el cual hace alusión al diseño y construcción de los contenedores donde son transportados los animales. En él, se especifica que deberán estar construidos de tal manera que los animales tengan un espacio adecuado para levantarse, estando el techo a una altura razonable para una correcta circulación del aire. Además, si es necesario será preferible que contengan particiones (rejas) para evitar el movimiento excesivo de los animales durante el traslado. Por otro lado, un importante punto a destacar es el plan de viaje, regulado en el art. 7. De conformidad con el mismo, cuando el viaje de ganado bovino, ovino, caprino y porcino exceda de ocho horas, la persona responsable del transporte deberá redactar un documento especificando los datos del transportista, del transporte, de las especies que se trasladan, el número de animales y los certificados veterinarios, el lugar de salida, de llegada, así como los puntos de parada donde los animales serán descargados para descansar.

Pasando a las Recomendaciones del Comité de Ministros del Consejo de Europa, fijaron su atención en el transporte de aves de corral en 1990. En ella, aparte de las especificaciones generales, contiene puntualizaciones con respecto a la carga de las gallinas ponedoras que ya han superado su "vida útil" (sí, efectivamente, como si fuera un producto listo para ser desechado y no un ser sintiente), los pollos de engorde o los pollitos de un día. Estos últimos, podrán ser trasladados en cajas de plástico (muy similares a esas en las que se transporta la 
verdura) con una altura y espacio aceptable de $10 \mathrm{~cm}^{2}$ y $21 \mathrm{~cm}^{2}$, respectivamente, por cada pollito. En cuanto a las condiciones de transporte del resto de aves, no corren mejor suerte. A modo de ejemplo, la Recomendación habla de que pueden ser cargadas a mano, cogidas por las patas con la cabeza boca abajo, aconsejando hasta tres aves por mano de cada trabajador encargado de esta tarea. Por si fuera poco, advierte que las "gallinas de desecho" (spent hens) son muy susceptibles de sufrir fracturas de huesos cuando son cargadas en los contenedores.

Visto todo lo anterior, lo cual ha sido una mínima parte de lo que ocurre en el día a día en este sector, no es necesario considerarse una persona defensora de los animales para llegar a la conclusión de que las condiciones de los animales en su transporte son inmensamente mejorables.

Por otra parte, fue determinante la Directiva 98/58/CE del Consejo, de 20 de julio de 1998, relativa a la protección de los animales en las explotaciones ganaderas. La trascendencia de esta norma recae en dos cosas. Por un lado, es fruto de toda la legislación anterior en esta cuestión, reflejando lo que se había estado avanzando tanto a nivel de normativa de la Unión Europea como del Consejo de Europa. Por otro, marca las bases conforme a las cuales se han estado elaborando textos normativos en dicha materia.

La Directiva, lamentablemente, presenta la misma orientación hacia el interés económico que el resto de normativa. A pesar de su título, tal y como se desprende de uno de los Considerandos el enfoque prioritario es garantizar el desarrollo de la producción y facilitar la organización del mercado de animales. A tal fin, se tendrán en cuenta las condiciones en materia de bienestar animal, y no esto último como interés directo. Su art. 1 preceptúa que no será de aplicación a los animales que viven en el medio natural; a los que participen en competiciones, actos, actividades culturales y eventos deportivos; a los que sean utilizados para experimentación o a los animales invertebrados.

El articulado de la Directiva es más formalista que otra cosa, versando la mayoría de sus artículos sobre elaboración de informes, propuestas o proyectos de medidas que deban tomarse. Es destacable su art. 5, disponiendo que la Comisión presentara al Consejo un informe cada 5 años. Además, el art. 6 prevé que las autoridades competentes de los Estados miembros lleven a cabo inspecciones en aras de comprobar el cumplimiento de lo contenido en la Directiva. De igual modo, deberán presentar a la Comisión un informe sobre estas inspecciones.

Cualquier persona podría esperar que la protección de los animales se desarrollara en todo el articulado. Empero, esto ha ido a parar al Anexo, sin traer nada nuevo que pueda llegar a considerarse un avance en el estado y trato de los animales. Es una lástima que un texto cuyo objetivo era dar las normas generales para la protección de las especies utilizadas en la ganadería haya sido tan poco ambicioso, desaprovechando la oportunidad de cambiar poco a poco el rumbo hacia un mayor respeto de los mismos. Por si fuera poco, es imposible no encontrar contradicciones como la presentada a continuación, acerca de la libertad de movimiento. De hecho, es difícil comprender por qué este tema comienza con: "No se limitará la libertad de movimientos propia de los animales (...) de manera que se les cause sufrimiento o daños innecesarios", cuando el siguiente párrafo continúa así: "Cuando los animales se encuentren atados, encadenados o retenidos continua o regularmente...". Quizás piensen que permanecer continuamente encadenado no es un sufrimiento innecesario.

Continuando con el orden cronológico, en 2004 ve la luz el Reglamento 1/2005 del Consejo, de 22 de diciembre de 2004, relativo a la protección de los animales durante el transporte y las operaciones conexas. Por cuanto hace a su ámbito de aplicación, incluye los casos de transporte de vertebrados vivos dentro de la Unión Europea, siempre que se efectúe en 
relación con una actividad económica, excluyendo el transporte de animales directamente desde o hacia clínicas veterinarias, por consejo de un veterinario (art. 1). Asimismo, se indica que únicamente resultarán aplicables los artículos 3 (condiciones generales aplicables al transporte de animales) y 27 (inspecciones e informes anuales de las autoridades competentes) en dos casos:

1. En el transporte de animales realizado por agricultores que utilicen medios de transporte que les pertenezcan, en casos en que las circunstancias geográficas exijan un transporte para la trashumancia estacional de determinados tipos de animales.

2. En el transporte de animales que realicen los ganaderos de sus propios animales, con su propio medio de transporte, a una distancia de explotación inferior a $50 \mathrm{~km}$.

Lo previsto en el presente Reglamento perfectamente podría considerarse como una concreción de los principios básicos detallados en el ya mencionado Convenio Europeo para la protección de los animales durante el transporte internacional, revisado en 2003. Así, tras un primer Capítulo en donde se encuentran las condiciones generales aplicables al transporte de los animales, los Capítulos II y III cobran relevancia en cuanto al desarrollo exhaustivo de cuestiones más bien técnicas o administrativas. En el primero de ellos destaca la exigencia de llevar en el medio de transporte una documentación que acredite, entre otros datos, el origen y propietario de los animales, el lugar de salida y destino, o la duración prevista del viaje. En cuanto al Capítulo III, su trascendencia recae en que versa sobre los requisitos que deben tener los transportistas para obtener la oportuna autorización para transportar animales por la autoridad competente, así como la potestad de esta última para realizar controles de manera aleatoria o sistemática en el caso de viajes largos.

Sin embargo, lo más valioso de este Reglamento es su Anexo I sobre las Especificaciones Técnicas. A lo largo de siete capítulos se lleva a cabo una delimitación de las normas que han de observarse en aspectos del transporte tan esenciales como son la aptitud de los animales para viajar, las exigencias que deben cumplir los distintos medios de transporte, las prácticas del mismo (es decir, lo referente a la carga, descarga y manipulación de los animales, o la duración del trayecto), los intervalos de suministro de agua, alimentación, tiempo de viaje y descanso que se deben respetar, así como el espacio mínimo que deben disponer para viajar, dependiendo de la especie de que se trate.

Especial atención merece la duración de los viajes y el espacio disponible, por cómo esto puede llegar a causar un grave perjuicio a los animales. Partiendo de la base de que el art. 2 del Reglamento entiende por "viaje largo", un viaje cuya duración supere las ocho horas a partir del momento en que se traslada al primer animal de la partida, el Capítulo V del Anexo I, relativo a los intervalos de suministro de agua, alimentación, tiempo de viaje y descanso, permite que animales como los cerdos puedan transportarse durante 24 horas, siempre que el medio de transporte esté equipado para viajes largos, de conformidad con las disposiciones complementarias del Capítulo VI. Sin embargo, esta "equipación" deja bastante que desear, sobre todo porque las previsiones de pienso, provisión de agua o ventilación se ven opacadas cuando se prevé un espacio para éstos, en el Capítulo VII, suficiente únicamente para poder tumbarse. No se encuentran en mejor condición el resto de animales, puesto que se permite en el transporte por carretera menos de 1 metro cuadrado para terneros de 200 kilos o 0,30 metros cuadrados para ovejas esquiladas de más de 55 kilos.

Por otro lado, dentro de este mismo Anexo, en el Capítulo III, se recogen disposiciones acerca de la carga, descarga y manipulación de animales. Estas situaciones son las que pueden llegar a generar mayor controversia, debido a que el animal se ve en una situación de enorme 
estrés al tener que actuar contra su propia voluntad. Así, para manipularlos, están expresamente prohibidas prácticas como golpearlos o darles patadas, colgarlos por medios mecánicos o utilizar pinchos u otros instrumentos puntiagudos. Lamentablemente, esta forma de tratarlos está a la orden del día, puesto que los transportistas y el resto de intervinientes en el proceso deben de cumplir horarios y objetivos, por lo que no pueden permitirse perder el tiempo en los momentos de carga y descarga. Del texto se desprende la posibilidad de utilizar en bovinos y porcinos descargas eléctricas para que se muevan, así como atar a los animales durante el transporte con cuerdas u otros medios que permitan, si es necesario, tumbarse (tampoco es una exigencia en la mayoría de los viajes que el animal pueda acostarse...).

Finalmente queda el momento de la matanza, que se regula a través del Reglamento (CE) 1099/2009 del Consejo, de 24 de septiembre de 2009, relativo a la protección de los animales en el momento de la matanza, aplicable desde el 1 de enero de 2013. El enfoque economicista (esto es, conceder primacía a los factores económicos) ya se advierte en los Considerandos. Ejemplos de ello son el $\mathrm{n}^{\circ} 6$, al entender que no son económicamente viables las recomendaciones de la Autoridad Europea de Seguridad Alimentaria para eliminar progresivamente el uso de dióxido de carbono en la matanza de cerdos o el método de aturdimiento por "baño de agua" en las aves de corral (consiste en suspender a las aves de grilletes, cabeza abajo, y sumergirlas hasta las alas en un baño de agua, donde reciben una corriente eléctrica) ${ }^{25}$; o el $n^{\circ} 10$, entre otros, en donde se resalta que las condiciones de matanza de los animales mantenidos con fines de explotación ganadera influyen en el mercado de los alimentos y en la competitividad de las empresas del sector.

Su ámbito de aplicación (art. 1) está limitado a la matanza de animales criados para la producción de alimentos, lana, cuero, piel u otros productos, así como cuando se lleva a cabo con motivo de vaciado sanitario (de acuerdo con el art. 2, se trata del proceso de matanza por razones de salud pública, animal, bienestar de éstos o medio ambiente). Los casos excluidos del presente Reglamento son:

1. Cuando los animales son matados durante experimentos científicos, en actividades de caza o pesca recreativa y en acontecimientos culturales o deportivos.

2. Si el dueño de aves de corral, conejos o liebres las sacrifica fuera de un matadero para su consumo doméstico privado.

No tener en consideración el sacrificio por un particular y la exclusión casi por completo de la matanza de peces en piscifactorías (solo les resultaría aplicable a estos últimos el requisito general del art. 3.1, es decir, que durante la matanza no se les cause dolor, angustia o sufrimiento evitable) conlleva una vulneración de los postulados esenciales sobre bienestar animal. En el primer caso, porque normalmente cuando se sacrifican aves, conejos o liebres para consumo privado, se emplean métodos tradicionales en los cuales no se tiene en cuenta el sufrimiento del animal. En el segundo, porque diversos estudios avalan que los peces son seres sintientes $^{26}$, por lo que también son víctimas del estrés, el dolor o la angustia que generan las condiciones de las piscifactorías y su posterior matanza.

\footnotetext{
${ }^{25}$ En su Informe al Parlamento Europeo y al Consejo relativo a los distintos métodos de aturdimiento para las aves de corral (2013), la Comisión Europea consideró que la eliminación progresiva del aturdimiento por baño de agua no era una opción económicamente viable por ahora. Puede verse el informe aquí: https://eurlex.europa.eu/resource.html?uri=cellar:4a783271-76c6-11e3-b889-01aa75ed71a1.0008.01/DOC_1\&format=PDF.

26 Entre otros: BROWN, C., "Fish pain: An inconvenient truth", Animal Sentience Journal, 2016, 1-2 (https://animalstudiesrepository.org/cgi/viewcontent.cgi?referer=\&httpsredir=1\&article=1069\&context=animsent);

BROOM, D. M., "Fish brains behavior indicate capacity for feeling pain", 2016, 1-3
} 
Antes de entrar en detalle, es indispensable mencionar qué se entiende por aturdimiento. De acuerdo con el art. 2, se trata de todo proceso que cause deliberadamente la pérdida de consciencia y sensibilidad sin dolor (aturdimiento simple), incluido el que provoque la muerte instantánea (aturdimiento propiamente dicho). Dicho esto, el art. 4 obliga a que los animales se maten únicamente previo aturdimiento y, si no causan la muerte instantánea, deberán ir seguidos de algún procedimiento como el sangrado, descabello (desgarrar el tejido nervioso central y la médula espinal al introducir en la cavidad craneal un instrumento en forma de vara alargada), la electrocución o la exposición prolongada a la anoxia (disminución de oxígeno en los tejidos del cuerpo o la sangre).

En este mismo art. 4, en su apartado 4, aparece uno de los puntos más polémicos de todo el Reglamento: la excepción de que no se utilice el aturdimiento previo en el caso de animales objeto de métodos particulares de sacrificio prescritos por ritos religiosos, siempre que se lleve a cabo en un matadero autorizado. La religión musulmana y la judía, a través del rito Halal y Kosher, respectivamente, exigen que los animales, en el momento de su sacrificio, se encuentren en perfecto estado de salud. Con esta exigencia, consideran que el animal aturdido podría ser considerado "enfermo", por lo que eluden la obligación de aturdirlo antes de sacrificarlo. Al animal se le inmoviliza y, sujetándole la cabeza, lo sacrifican cortándole el cuello, proceso que debe durar unos 40 segundos en total. En el caso de que el corte no se lleve a cabo adecuadamente, el tiempo que puede tardar en perder la consciencia el animal llega hasta casi 5 minutos. Esta inmovilización causa un enorme estrés al animal que ya está previamente asustado, por no hablar de que si el periodo de pérdida de consciencia se alarga a varios minutos, se vuelven interminables, provocando un dolor y sufrimiento totalmente innecesario. ${ }^{27}$

La prohibición de estos ritos en los que el animal está consciente cuando lo sacrifican, ya se ha conseguido en países como Suecia, Eslovenia, Dinamarca o Austria, entre otros, y parece que, tarde o temprano, se van a ir sumando más nombres a esa lista. Así, el ministro competente en materia de bienestar animal de la Región Flamenca, en Bélgica, prohibió en 2014 conceder autorizaciones a mataderos temporales para practicar ese tipo de sacrificios, lo cual, según la comunidad musulmana de la Región, vulneraba la libertad de religión contenida en el art. 10 de la Carta de Derechos Fundamentales de la Unión Europea, al aumentarse la demanda de carne Halal durante la Fiesta del Sacrificio o Eid Al-Adha, mayor acontecimiento anual del Islam. Finalmente, el Tribunal de Justicia de la Unión Europea ha resuelto el asunto mediante sentencia de 29 de mayo de 2018, determinando que este tipo de sacrificio solo puede realizarse en mataderos autorizados. ${ }^{28}$

El cambio se está viendo en la sociedad europea. La consideración de los animales como seres dotados de sensibilidad, que sufren y disfrutan, se está arraigando a pasos agigantados. La legitimación de causar un sufrimiento innecesario a los animales en base a creencias religiosas o motivos culturales tiene los días contados.

Desafortunadamente, en España estamos dando pasos hacia el lado contrario, por la oportunidad económica que representa la carne Halal. Casi 30.000 corderos y cabritos fueron sacrificados bajo este rito el año pasado en el matadero de Olivenza (Badajoz), junto a más de

(https://animalstudiesrepository.org/cgi/viewcontent.cgi?referer=\&httpsredir=1\&article=1031\&context=animsent); BALCOMBE, J., "Cognitive evidence of fish sentience", Animal Sentience Journal, 2016, 1-2 (https://animalstudiesrepository.org/cgi/viewcontent.cgi?referer=\&httpsredir=1\&article=1059\&context=animsent).

27 Asociación de Veterinarios Abolicionistas de la Tauromaquia y del Maltrato Animal, Informe matanza sin aturdimiento previo, 2017, 2-3 (https://avatmaorgblog.files.wordpress.com/2017/05/informe-matanza-sinaturdimiento-previo-6-12-2017.pdf)

${ }^{28}$ La sentencia: http://curia.europa.eu/juris/celex.jsf?celex=62016CJ0426\&lang1=es\&type=TXT\&ancre 
6.300 vacas. La mayoría de la producción acaba en países árabes, como Emiratos Árabes, Arabia Saudí o Qatar. ${ }^{29}$ Por otro lado, según la Federación de Industrias Cárnicas (Fecic), en Cataluña casi el $50 \%$ del cordero y más del $40 \%$ del vacuno se sacrifican por el rito halal, debido al aumento de la demanda en España y la posibilidad de abrirse a un mercado exterior muy rentable para estas empresas. ${ }^{30}$

Tras haberse detenido en este asunto tan controvertido, resalta por su vinculación a la preocupación del bienestar animal el art. 7, de cuyo contenido se desprende la necesidad de que las operaciones de sacrificio como son por ejemplo la sujeción de los animales para aturdirlos o matarlos y el aturdimiento mismo, sean realizadas por personas que tengan un certificado de competencia emitido por la autoridad competente de conformidad con lo establecido en el art. 21.

Por último, parece que la mejor forma de concluir este apartado sobre bienestar animal en la ganadería industrial a nivel de normativa europea es mencionando brevemente los distintos métodos de aturdimiento, enumerados en el Anexo I de este Reglamento. Éstos se encuentran clasificados en métodos mecánicos, eléctricos, de gas y la inyección letal, disponiendo también requisitos específicos para algunos métodos. Para cualquier persona con un mínimo de empatía hacia los animales, leer en un texto la descripción y condiciones de uso de semejantes prácticas, transmite una frialdad difícil de digerir. De entre los métodos mecánicos llaman la atención la "trituración" y la "pistola de perno cautivo penetrante". El primero, consistente en una trituración inmediata de todo el animal, es utilizado para polluelos de hasta 3 días de vida y algunos de los parámetros a tener en cuenta son la distancia entre las cuchillas y su velocidad de rotación. De sus requisitos específicos se desprende que "la capacidad del aparato deberá ser suficiente para matar instantáneamente a todos los animales incluso si su número es elevado".

Por lo que respecta al segundo, se trata de un método de aturdimiento simple y consiste en una pistola que dispara una pequeña pieza de metal cilíndrica, normalmente activada por aire comprimido. Al penetrar en el cráneo y producir un daño cerebral grave e irreversible, es importante la posición de la pistola, cuya ubicación correcta varía en función de la especie. Con esto, no es difícil descifrar que este método puede llegar a causar lesiones graves y no el aturdimiento del animal si no es efectuado adecuadamente, lo cual puede deberse a la fatiga del operario, la falta de precisión o al movimiento del animal si no está debidamente inmovilizado.

Más impactantes que lo descrito en el párrafo anterior, son los requisitos específicos previstos para el uso del monóxido de carbono (ya sea fuente pura o asociado a otros gases), utilizado como método de aturdimiento que causa la muerte en animales de peletería, aves de corral y cochinillos. Así, se precisa que los animales se introducirán en la cámara uno por uno, permaneciendo en ella hasta que estén muertos. Se puede utilizar el gas producido por un motor adaptado para matar animales, siempre que la persona responsable de matarlos haya comprobado que el gas utilizado esté exento de componentes irritantes. Un método de exterminio sencillo, rápido y limpio, que no requiere mancharse las manos de sangre para matar al animal. No hay nada más eficaz que erradicar por completo la empatía.

\footnotetext{
29 "Extremadura sacrifica por el rito hala para vender carne a los emiratos": https://www.efe.com/efe/espana/sociedad/extremadura-sacrifica-por-el-rito-halal-para-vender-carne-a-losemiratos/10004-3577063. Fecha de acceso: 07-07-2018.

30 "El tirón de la carne halal dispara el sacrificio de animales sin aturdimiento en España": http://www.publico.es/sociedad/maltrato-animal-tiron-carne-halal-dispara-sacrificio-animales-aturdimientoespana.html. Fecha de acceso: 07-07-2018.
} 
Habiendo abarcado la legislación general relacionada con el bienestar animal a nivel europeo, a continuación van a ser analizados algunos textos normativos europeos que están enfocados específicamente en distintas especies de animales.

\section{II.1.1.1 Cerdos}

La Directiva 2008/120/CE del Consejo, de 18 de diciembre de 2008, relativa a las normas mínimas para la protección de cerdos, dispone las bases para la protección de cerdos confinados para la cría y el engorde (art. 1). Lo más destacable de esta Directiva es su art. 3, donde se establecen los requisitos que deben cumplir las explotaciones en los Estados miembros, relativos a la superficie que debe disponer cada animal. A modo de ejemplo, para un cerdo de producción (más de 10 semanas de edad) criado en grupo y que pese nada menos que $110 \mathrm{~kg}$., se permite que solo tenga $1 \mathrm{~m}^{2}$ de suelo libre. Las cerdas no corren mejor suerte, puesto que está admitida una superficie de $2,25 \mathrm{~m}^{2}$ y $1,64 \mathrm{~m}^{2}$, dependiendo de si se trata de una cerda joven después de la cubrición (apareamiento de los animales, puede ser realizado mediante inseminación artificial de la hembra) o después del parto, respectivamente. En su apartado 4 se permite que las cerdas durante el periodo comprendido entre las 4 semanas siguientes a la cubrición y los 7 días anteriores a la fecha de parto, se críen en grupos mantenidos en celdas de 2,8 metros de lado. El hacinamiento, aburrimiento y la falta de espacio tienen como consecuencia conductas agresivas entre ellas y peleas por la comida.

Por otro lado, no se puede obviar el gran problema que supone en estos animales la caudofagia. Consiste básicamente en un trastorno del comportamiento de los cerdos que se manifiesta con la mordedura de colas de unos cerdos a otros. Este trastorno es una respuesta al aburrimiento, frustración y la estimulación insuficiente del animal, en resumen, a las condiciones de vida en la mayoría de explotaciones ganaderas industriales. Una gestión económica, rápida y, sobre todo, siniestra, es el raboteo: amputar el rabo del animal. Práctica enormemente dolorosa, la cual se debe llevar a cabo con anestesia pero que muchas veces incluso se realiza sin ella, no elimina la alteración de comportamiento de los cerdos. ${ }^{31}$ Con el ánimo de atajar este problema se dictó la Recomendación (EU) 2016/336 de la Comisión, de 8 de marzo de 2016, de medidas para disminuir la necesidad de practicar el raboteo. Sin embargo, medidas como que dispongan de cantidad suficiente de materiales para que puedan explorar y manipular (paja, heno, serrín) son meros parches y parecen tener la intención de apartar el enfoque sobre el verdadero problema: la perpetuación de un sistema de producción industrial en el que prima la evolución del sector económico, llevando a cabo, si es necesario, amputaciones como esta a los animales.

\section{II.1.1.2 Terneros}

De muy similar redacción y estructura que la Directiva referente a los cerdos, para los terneros (animal bovino de hasta 6 meses de edad) existe la Directiva 2008/119/CE del Consejo, de 18 de diciembre de 2008, relativa a las normas mínimas para la protección de terneros.

\footnotetext{
${ }^{31}$ Un análisis más exhaustivo de la caudofagia se encuentra en el Documento sobre la gestión de las explotaciones porcinas para evitar la caudofagia (2017), elaborado por el Ministerio de Agricultura y Pesca, Alimentación y Medio Ambiente. Se puede encontrar en el siguiente enlace: http://www.mapama.gob.es/es/ganaderia/temas/produccion-ymercados-ganaderos/20171031documentosobregestiondelasexplotacionesparalaprevenciondelraboteo_tcm30441875.pdf.
} 
Reuniendo las normas mínimas para la protección de terneros confinados para la cría y engorde (art. 1), especial atención merece el art. 3, tal y como se hacía mención para los cerdos, en donde se preceptúa que "no se mantendrá encerrado a ningún ternero de más de 8 semanas de edad en recintos individuales, a menos que un veterinario haya certificado que su salud o comportamiento requiere que se le aisle". Por lo tanto, se aprecia que los terneros de menos de 8 semanas efectivamente podrían estar encerrados en un "alojamiento" (así se atreven a llamar a un espacio apenas más grande que su tamaño) individual.

En cambio, si son criados en grupo, el espacio por cada ternero oscila entre $1,5 \mathrm{~m}^{2}$ y 1,8 $\mathrm{m}^{2}$, dependiendo del peso del animal.

Aparte de lo expuesto anteriormente, dentro de su Anexo I es obligatorio, por su evidente transgresión al estado de ánimo del animal, citar el apartado 5: "No se mantendrá permanentemente a los terneros en la oscuridad. (...) se dispondrá, teniendo en cuenta las distintas condiciones climáticas de los Estados miembros, de una iluminación adecuada natural o artificial, equivalente al menos, en el segundo caso, al tiempo de iluminación natural disponible entre 9:00 h. y 17:00 h.". Bien, leyendo entre líneas, esto lo que realmente significa es que la mayoría de terneros que viven en granjas industriales no va a ver la luz del sol durante su corta vida. Bueno, claro está, probablemente aproveche algunos rayos de sol antes de ser transportado hacia el matadero.

\section{II.1.1.3 Gallinas ponedoras y pollos para la producción de carne.}

Mismo sistema, dos Directivas para establecer las normas mínimas de protección: por un lado, la Directiva 1999/74/CE, de 19 de julio de 1999, para las gallinas ponedoras; y por otro, la Directiva 2007/43/CE, de 28 de junio de 2007, para los pollos destinados a la producción de carne, ambas emanadas del Consejo.

Por lo que corresponde a las gallinas ponedoras, el art. 1 de la Directiva deja fuera de su regulación los establecimientos de menos de 350 gallinas ponedoras, así como los de cría de gallinas ponedoras reproductoras. El texto recoge tres sistemas: alternativos, jaulas acondicionadas y no acondicionadas. El que, sin lugar a dudas, hace saltar las alarmas es este último. No obstante, esto no significa que los sistemas alternativos estén a la vanguardia de bienestar animal: $1 \mathrm{~m}^{2}$ por cada 9 gallinas ponedoras, nidos colectivos de $1 \mathrm{~m}^{2}$ para 120 gallinas o la posibilidad (en la mayoría de los casos) de que no tengan acceso a espacios exteriores son condiciones, cuanto menos, mejorables.

$550 \mathrm{~cm}^{2}$ (¡menos que un folio!) de superficie de jaula por gallina, $10 \mathrm{~cm}$ de espacio en el comedero continuo, $40 \mathrm{~cm}$ de altura de las jaulas o el suelo de red de alambre son las características de esas jaulas no acondicionadas. El art. 5.2 dispone que los Estados miembros velarán por que la cría en estas jaulas se prohibiera a partir del 1 de enero de 2012. Desafortunadamente, las jaulas "acondicionadas" no mejoran en absoluto las condiciones deplorables en las que viven las gallinas, únicamente asciende la superficie que puede utilizar cada una a $600 \mathrm{~cm}^{2}$ (sigue siendo menos que el área de un folio, jimposible estirar las alas!), disponen de un nido, material para escarbar y... jvaya! aumenta en $2 \mathrm{~cm}$ el espacio que tiene cada una en el comedero. El suelo sigue siendo de red de alambre y el Anexo nos deja una advertencia: "los excrementos deberán retirarse con la frecuencia que sea necesaria y las gallinas muertas diariamente". 
Respecto a las explotaciones de pollos destinados a la producción de carne, pueden tener una densidad máxima de población de $39 \mathrm{~kg} / \mathrm{m}^{2}$. Si el peso medio de cada pollo "de engorde" es de $2,5 \mathrm{~kg}$., estarían compartiendo ese espacio nada menos que 15 animales. Seleccionados genéticamente, el ritmo vertiginoso de crecimiento al cual son sometidos para un mayor beneficio económico provoca que sus patas no aguanten semejante peso, dificultando su movilidad y padeciendo enfermedades genéticas (apartado 9, Anexo I: "los pollos con lesiones graves o con señales evidentes de trastornos de salud que puedan causar dolor, como los que presenten dificultades para andar, (...) serán inmediatamente sacrificados.”). La edad en la que están listos para el matadero ronda los... 41 días. Este crecimiento para maximizar la producción es propiciado por disposiciones como el apartado 7 del Anexo I, consistente en una alteración del ciclo de luz y oscuridad: permite a partir del $7^{\circ}$ día desde el que se deposite a los pollos en la explotación y hasta 3 días antes de su sacrificio, 6 horas de oscuridad y 18 de luz, evidentemente, artificial.

Y, como muestra de que la odisea de estos animales está plagada de sufrimiento desde sus inicios, ambas Directivas permiten la posibilidad de recortar el pico (sin anestesia) sobre polluelos de menos de 10 días.

\section{II.1.2 El bienestar animal y los animales de compañía}

El Convenio Europeo sobre protección de animales de compañía, hecho en Estrasburgo el 13 de noviembre de 1987, entiende por animal de compañía todo aquel que sea tenido o esté destinado a ser tenido por una persona, en particular en su propia vivienda, para que le sirva de esparcimiento y le haga compañía.

Factores sociales y culturales en los cuales no se va a entrar en detalle por motivos de extensión han llevado a una diferencia de trato abismal entre los animales vistos hasta ahora y los considerados de compañía. Este texto es considerado como la base para las legislaciones nacionales de los Estados miembros, los cuales pueden implementar medidas más estrictas encaminadas a proteger a los animales de compañía. Algunos de los puntos fundamentales de su articulado son los siguientes:

1. Toda persona que tenga un animal de compañía o que haya aceptado ocuparse de él será responsable de su salud y bienestar (art. 4.1).

2. No puede venderse un animal de compañía a menores de 16 años sin consentimiento expreso de sus padres o personas que ejerzan la patria potestad (art. 6).

3. Se prohíben las intervenciones quirúrgicas cuya finalidad sea modificar la apariencia u otros fines no curativos (art. 10.1).

4. Solo podrán ser sacrificados por un veterinario o persona competente, salvo en casos de urgencia (art. 11.1).

5. El compromiso de los Estados por reducir la reproducción no planificada de perros y gatos estimulando su esterilización (art. 12. b. ii.).

El art. 6 respecto a la edad para adquirir animales y el art. 10.1 relativo a las intervenciones quirúrgicas cuyo único objeto sea modificar la apariencia (corte de cola, orejas, extirpación de uñas y dientes) se convierten en meras declaraciones de intenciones por cuanto el art. 21 permite a los Estados formular reservas para no aplicarlos. Entre las reservas, a modo de 
ejemplo encontramos que Dinamarca y Francia declaran que no están vinculados por la prohibición de cortar la cola.

En relación con estos animales de compañía, es destacable el Reglamento 1523/2007 del Parlamento Europeo y del Consejo, de 11 de diciembre de 2007, por el que se prohíbe la comercialización y la importación a la Comunidad, o exportación desde esta, de pieles de perro y de gato y de productos que las contengan. La única excepción contenida en este Reglamento se localiza en el art. 4, determinando que se podrá comercializar e importar o exportar con fines educativos o de taxidermia (disecado de animales).

Otro texto que cobra relevancia, sobre todo por el aumento de adopciones entre Estados miembros de estos animales, es el Reglamento 576/2013 del Parlamento Europeo y del Consejo, de 12 de junio de 2013, relativo a los desplazamientos sin ánimo comercial de animales de compañía. De su contenido se infiere que los animales de compañía deberán cumplir, salvo excepciones, las siguientes condiciones: que estén marcados mediante un dispositivo de identificación o tatuaje; que hayan sido vacunados contra la rabia, según la especie; si es necesario, que cumplan las medidas sanitarias preventivas contra enfermedades o infecciones distintas de la rabia y que vayan acompañados de un documento de identificación cuyo contenido se especifica en el art. 21 (características del animal, datos del propietario, del veterinario que expida el documento, etc.).

\section{II.2 Normativa estatal}

En este apartado se procederá al análisis de la normativa española en lo referente a bienestar animal ${ }^{32}$ a través de la misma estructura seguida en el anterior. Antes de comenzar, resulta vital tener bien presente que la mayoría de la normativa estatal que se verá a continuación, o ha sido modificada para atenerse a los postulados emanados de las normas europeas, o bien constituye una incorporación de las mismas.

Tal y como vaticinábamos al comienzo de la exposición de esta segunda parte del trabajo, los mayores atentados al estado de los animales se producen en torno a la ganadería industrial, por lo que las próximas páginas versarán sobre las normas españolas íntimamente implicadas en el bienestar animal en la ganadería industrial, para después pasar al bienestar animal y los animales de compañía. Misma estructura, mismos objetivos: poner sobre la mesa que el enfoque bienestarista en la legislación es insuficiente, que la concepción social de los animales como meros productos o seres que podemos utilizar para nuestro propio interés económico está cambiando a un ritmo imparable, y que el Derecho tiene que estar a la altura de las circunstancias.

Especial complejidad, por el tema que regula, ostenta la Ley 8/2003, de 24 de abril, de sanidad animal. La prevención, lucha, control y erradicación de las enfermedades de los animales constituyen el núcleo de este texto. Para ello, abarca desde las obligaciones de los particulares, pasando por las inspecciones de frontera, la importación, exportación, hasta los requisitos y condiciones de sanidad animal que deben estar presentes en los distintos agentes que intervienen en el mercado de animales: explotaciones, el transporte y los mataderos.

\footnotetext{
${ }^{32}$ Este tema ha sido ampliamente trabajado desde el derecho administrativo. Destacan: PÉREZ MONGUIÓ, J. M., "Marco jurídico de la protección animal en España desde 1929 hasta 2015. El lento y firme trote del mastín", Revista Aranzadi de derecho ambiental, 2015, 32, 285-333; "Antecedentes históricos jurídicos-administrativos de la protección animal en España”, Animalia: revista profesional de los animales de compañía, 2009, 216, 52-55.
} 
El hacinamiento, la falta de limpieza, el comercio intracomunitario y el incumplimiento de los estándares mínimos europeos conforman una serie de factores que convierten las explotaciones ganaderas en auténticos caldos de cultivo de enfermedades infecto-contagiosas, cuya prevención es llevada a cabo con un incremento de fármacos a los animales. Esto cercena el sistema inmunológico de los mismos y, no solo eso, sino que puede conllevar también un grave perjuicio a la salud de las personas que consumen carne o productos ganaderos. El legislador, consciente de este problema, dedica el Título IV de la ley a los productos zoosanitarios y para la alimentación animal.

La siguiente ley acata fielmente la obligación por parte de la Unión Europea de regular un régimen sancionador para aquellos casos en los que se incumpla la normativa de bienestar animal, encargándose también de fijar un conjunto de principios sobre el cuidado de los animales que son un pequeño reflejo de todo lo visto hasta ahora en la normativa europea, siendo ésta en muchos casos directamente aplicable.

Así, la Ley 32/2007, de 7 de noviembre, para el cuidado de los animales, en su explotación, transporte, experimentación y sacrificio, bien podría haberse denominado de otra forma. Esto es así porque el Título I, relativo a la explotación, transporte, experimentación y sacrificio, con apenas 6 artículos, pasa completamente desapercibido, con numerosas remisiones a la normativa europea. El grueso de esta ley y lo verdaderamente a destacar es su régimen sancionador, previsto en el Título II, intitulado de las inspecciones, infracciones y sanciones.

Tras una referencia sobre el personal inspector y las obligaciones del inspeccionado (como, por ejemplo, permitir el acceso de los inspectores a la explotación, instalación o medio de transporte con la finalidad de realizar su actuación inspectora), se encuentran las infracciones y sanciones. Las primeras, comprendidas en el art. 14, se clasifican en muy graves, graves y leves. Son infracciones muy graves, entre otras, las siguientes:

a) Utilizar los animales en peleas.

b) El incumplimiento de la obligación de aturdimiento previo, cuando no concurra el supuesto de ritos propios de Iglesias, Confesiones o Comunidades religiosas inscritas en el Registro de Entidades Religiosas.

c) Suministrar documentación falsa a los inspectores o a la Administración.

d) Utilizar perros o gatos vagabundos en procedimientos.

Dentro de las infracciones graves, resaltan las mutilaciones no permitidas a los animales o el incumplimiento de las obligaciones exigidas por las normas de protección animal, cuando produzca lesiones permanentes, deformaciones o defectos graves de los mismos. Por último, la oposición, obstrucción o falta de colaboración con la actuación inspectora de control de las Administraciones Públicas, cuando no impida o dificulte gravemente su realización, constituye una infracción leve.

Por lo que hace a las sanciones (art. 16), para el caso de infracciones leves, hasta $600 €$, infracciones graves, de 601 a $6.000 €$, y muy graves, de 6.001 a $100.000 €$. Es apreciable el apartado 3 de este artículo, donde se expresa que "los ingresos procedentes de las sanciones se destinarán a actuaciones que tengan por objeto la protección de los animales”.

Continuando con la enumeración cronológica de textos legales, si bien el Reglamento 1099/2009, del Consejo, de 24 de septiembre de 2009, relativo a la protección de los animales en el momento de la matanza, es de directa aplicación, el Real Decreto 37/2014, de 24 de enero, 
por el que se regulan aspectos relativos a la protección de los animales en el momento de la matanza surge como una necesidad en aras de establecer una serie de disposiciones específicas de aplicación en España del mencionado Reglamento, en lo relativo a (art. 1):

a) La formación de las personas que realizan la matanza y las operaciones conexas a ella.

b) Algunos aspectos de la matanza de animales en las explotaciones dedicadas a la producción de animales de peletería y en las que se maten pollitos de hasta 72 horas o huevos embrionados, así como del vaciado sanitario.

c) Requisitos mínimos para realizar la matanza de emergencia fuera del matadero y para consumo doméstico privado.

d) Comercialización en España de productos de equipamiento de sujeción y aturdimiento.

A lo largo del articulado se aprecia una remisión continua al Reglamento, por lo que este texto legal constituye más bien una especificación de ciertos puntos que aquél no contempla o contempla de forma más genérica.

Semejante situación se manifiesta en la protección de los animales durante el transporte. La norma básica en esta materia en la Unión Europea es el Reglamento 1/2005, del Consejo, de 22 de diciembre de 2004, habiendo sido ya oportunamente analizado. Con igual intención que el anterior Real Decreto, en este ámbito el Real Decreto 542/2016, de 25 de noviembre, sobre normas de sanidad y protección animal durante el transporte ofrece una serie de normas de aplicación en España del Reglamento 1/2005, en lo concerniente a los aspectos previstos en el art. 1.

También en este caso se percibe una constante alusión al Reglamento 1/2005, por lo que su misión es más bien de completar apartados sobre la materia que el Reglamento haya remitido a los Estados miembros. Cabe nombrar la duración de las autorizaciones de transportistas y medios de transporte, que será como máximo de 5 años a partir de la fecha de expedición. Asimismo, su validez queda condicionada al mantenimiento de las condiciones que fueron exigidas para su concesión.

\section{II.2.1 El bienestar animal en la ganadería industrial}

Si bien las normas precisadas en los párrafos anteriores podrían ser perfectamente 


\section{II.2.1.1 Cerdos}

Atendiendo a las estadísticas del Ministerio de Agricultura, Pesca y Alimentación, en el primer semestre de este año 2018 la cantidad de cerdos sacrificados asciende a la aterradora cifra de 18 millones. Una bajada de 7 millones de animales matados en este mismo periodo con respecto al 2017, año muy productivo para el sector de la ganadería porcina. ${ }^{33}$

Sentado lo anterior, era de esperar que el Real Decreto 324/2000, de 3 de marzo, por el que se establecen normas básicas de ordenación de las explotaciones porcinas, comenzara con subrayar la importancia de las explotaciones españolas de ganado porcino. De acuerdo con datos de Eurostat, en 2017 fuimos el segundo país de la Unión Europea que más cerdos mató, casi 50 millones, solo por detrás de Alemania, con una cifra en torno a los 58 millones. ${ }^{34}$

De marcada orientación económica, este Real Decreto proporciona una serie de condiciones mínimas de funcionamiento de las explotaciones, sobre, entre otras cosas, el equipamiento e infraestructura de las mismas, la gestión de los estiércoles (lo cual genera un grave problema medioambiental por el alto riesgo de contaminación de aguas superficiales y subterráneas, así como del aire), la ubicación de las instalaciones, la distancia mínima entre ellas con el fin de reducir el riesgo de difusión de enfermedades infecto-contagiosas y las limitaciones por densidad ganadera en determinadas zonas. También incluye cuestiones más administrativas como por ejemplo la previsión de un Registro estatal de explotaciones porcinas.

Desde otro ángulo, pero nunca perdiendo el objetivo económico, está el Real Decreto $1135 / 2002$, de 31 de octubre, relativo a las normas mínimas para la protección de cerdos. Al tratarse de una incorporación de anteriores Directivas europeas en la materia, y para evitar reiteración, es conveniente remitirse a lo expuesto sobre la Directiva 2008/120/CE del Consejo. Únicamente recordar, para no perder el ánimo de dejar en evidencia la terrible condición en la que viven estos animales, varias cosas:

a) Las cerdas, para parir, por lo general son trasladadas a las famosas "parideras", jaulas en las que no pueden moverse, pensadas exclusivamente para amamantar a sus crías.

b) En muchas ocasiones, los lechones (denominado así desde el nacimiento hasta el destete) mueren aplastados por su propia madre, por culpa de la falta de espacio y la incapacidad de movimiento de ésta. Son separados de ella a los 28 días, o incluso a los 21 , si son trasladados a instalaciones especializadas.

Lo anterior está previsto en el Anexo del Real Decreto, en concreto el Capítulo II, sobre

\section{II.2.1.2 Terneros}

No podía faltar, en primer lugar, tener presente el número de animales que se han matado en el primer semestre de 2018: casi 800.000, siendo esta cifra provisional. Aquí se

\footnotetext{
${ }^{33}$ Las estadísticas pueden obtenerse en la página web del Ministerio de Agricultura, Pesca y Alimentación Ministerio para la transición ecológica: http://www.mapama.gob.es/es/estadistica/temas/estadisticasagrarias/ganaderia/encuestas-sacrificio-ganado/. Fecha de acceso: 01-07-2018.

${ }^{34}$ http://ec.europa.eu/eurostat/web/agriculture/data/database. Fecha de acceso: 01-07-2018.
} 
incluyen machos y hembras, así como las vacas lecheras cuando dejan de ser productivas para la industria. ${ }^{35}$

Nuestra normativa estatal se reduce al Real Decreto 1047/1994, de 20 de mayo, relativo a las normas mínimas de protección de terneros, el cual fue una transposición a nuestro ordenamiento interno de la Directiva 91/629/CEE, del Consejo. El contenido del Real Decreto no dista de lo que se ha manifestado en relación con estos animales y la normativa europea, habiéndose modificado en 2010 para adaptarlo a la Directiva de 2008 sobre este tema.

\section{II.2.1.3 Gallinas ponedoras y pollos para la producción de carne}

663 millones de pollos broilers o "de engorde", 37 millones de gallinas, 24 millones y medio de pavos, 1 millón de patos y 38 millones de "otras especies". Estos números, que parecen irreales y cuestan de creer, son los animales sacrificados en España durante el 2016, último año del que se tienen cifras detalladas por especie. En 2018 tan solo desde enero hasta abril ya se habían matado 253 millones de aves (bueno, si sirve de consuelo, ha habido un descenso. En el mismo periodo de 2017 ya alcanzábamos las 374 millones de aves sacrificadas). ${ }^{36}$

Las gallinas ponedoras encuentran el "cuidado de su bienestar" en el Real Decreto $3 / 2002$, de 11 de enero, por el que se establecen las normas mínimas de protección de las mismas. Actuando como instrumento de incorporación de la Directiva 1999/74/CE, del Consejo, igualmente en este asunto se hace necesaria la remisión a lo dicho sobre este texto europeo.

En adición, se echa muy en falta que la preocupación por el estado de estos animales haya sido más contundente. Las jaulas acondicionadas no mejoran la situación (son jaulas de 0,2 $\mathrm{m}^{2}$, apiladas unas encima de otras, con ni siquiera el tamaño de un folio por animal y sin olvidar el suelo de alambre, lo que provoca graves heridas) y los sistemas alternativos no son dignos de aplaudir.

Por otro lado, los pollos destinados a la producción de carne disponen de su protección en el Real Decreto 692/2010, de 20 de mayo. Con un marcado carácter técnico, aquí ocurre lo mismo, incorpora al ordenamiento jurídico interno la ya analizada Directiva 2007/43/CE, del Consejo, de 28 de junio de 2007.

De esta normativa, resta por enfatizar un detalle contenido en el Anexo III, en lo referente al control y seguimiento de la mortalidad: se debe especificar la mortalidad diaria y la tasa de mortalidad diaria acumulada en explotaciones de densidad de población superior a 33 $\mathrm{kg} / \mathrm{m}^{2}$. Perfectamente legible entre líneas, esto refleja la realidad del día a día en una explotación de este tipo: muchos de los pollos ni siquiera llegan al matadero, mueren por la fractura de sus huesos (lo que les impide llegar a la comida), infecciones, afecciones cardíacas y respiratorias. Un mero coste de producción apenas significativo con respecto al gran beneficio que supone engordarlos tanto en tan poco tiempo.

\footnotetext{
${ }^{35} \mathrm{~V}$. nota 31.

${ }^{36}$ V. supra.
} 


\section{II.2.1.4 Conejos}

46 millones en 2017 y 15 millones en el periodo enero-abril de este año ${ }^{37}$ Sí, en España también se matan conejos, y muchos. Pero no solo para producción de carne, puesto que el Real Decreto 1547/2004, de 25 de junio, por el que se establecen normas de ordenación de las explotaciones cunícolas (actividad que implica la cría de conejos), también recoge expresamente las explotaciones dedicadas a la producción de animales para aprovechar su piel o pelo, las de cría de animales de compañía, para suelta o repoblación y las de cría de animales de experimentación. Un animal, como se aprecia, en el cual el ser humano ha visto enorme utilidad para su propio interés.

El texto se centra en las condiciones de ubicación, registro, infraestructura zootécnica, sanitaria y de equipamientos para desarrollar esta actividad ganadera, por lo que el bienestar de los propios animales queda relegado a un segundo plano. No sorprende, por lo tanto, que no se haga ni una referencia al tamaño mínimo que deben tener las jaulas donde se mantienen a los conejos. Tampoco ocurre esto en la Guía de buenas prácticas de higiene en explotaciones cunícolas, del antiguo Ministerio de Medio Ambiente y Medio Rural y Marino. ${ }^{38}$ Esto lleva a la permisibilidad en cuanto al hacinamiento de los animales en condiciones deplorables de limpieza, lo que causa granjas descuidadas en naves industriales ${ }^{39} \mathrm{o}$, incluso, mataderos clandestinos ${ }^{40}$.

\section{II.2.2 El bienestar animal y los animales de compañía}

España llega tarde, muy tarde. Países como Alemania, Luxemburgo, Noruega o Suecia, ya estaban vinculados por el Convenio Europeo sobre protección de animales de compañía desde el 1 de mayo de 1992, fecha de su entrada en vigor, según lo previsto en su art. 18.1. Aquí, recién lo estábamos firmando el 9 de octubre de 2015, y su aplicabilidad se ha hecho esperar hasta el 1 de febrero de 2018, 26 años después que nuestros colegas de Europa. El aspecto positivo es que, al no haber hecho España ninguna reserva, se prohíben las intervenciones quirúrgicas con objeto de modificar la apariencia de un animal de compañía o con otros fines que no sean curativos, como cortar la cola o las orejas (art. 10.1 del Convenio).

Como ya se ha hecho alusión al contenido de este Convenio en la parte de normativa europea, es preferible aprovechar este espacio para un análisis de la nueva proposición de ley de modificación del Código Civil, la Ley Hipotecaria y la Ley de Enjuiciamiento Civil, sobre el régimen jurídico de los animales, presentada por el Grupo Parlamentario Popular en el Congreso. ${ }^{41}$

\footnotetext{
${ }^{37}$ V. supra.

${ }^{38}$ La guía de buenas prácticas de higiene en explotaciones cunícolas, de 2011, puede descargarse desde la siguiente página web: http://www.mapama.gob.es/es/ganaderia/publicaciones/CBBPP_CUNICULTURA-2011-WEB_tcm30105270.PDF. Fecha de acceso: 02-07-2018.

39 "Aparecen un centenar de conejos muertos sin comida ni agua en una nave en Suances": http://www.europapress.es/cantabria/noticia-aparecen-centenar-conejos-muertos-comida-agua-nave-suances20170512110845.html. Fecha de acceso: 02-07-2018.

40 "Descubren un matadero de conejos clandestino en el sótano de un restaurante de Murcia": https://www.laopiniondemurcia.es/murcia/2017/07/06/descubren-matadero-conejos-clandestino-sotano/843117.html. Fecha de acceso: 02-07-2018.

${ }^{41}$ La proposición de ley presentada por el Grupo Parlamentario Popular, en su redacción original, puede leerse aquí: http://www.congreso.es/public_oficiales/L12/CONG/BOCG/B/BOCG-12-B-167-1.PDF\#page=1.
} 
La regulación del Código Civil dota a los animales del estatuto jurídico de cosas, lo cual, tras todo lo contemplado hasta hora en estas páginas, es algo totalmente incomprensible. Tal y como recalca la Exposición de Motivos de esta Proposición de Ley, esta reforma seguiría el camino de otras que se han dado en países europeos, como la belga en 2009, la francesa en 2015 o la portuguesa en 2017. Cumpliendo con la orientación de las normas europeas, lo que más sobresale de esta reforma sería el nuevo art. 333 del Código Civil, al considerar los animales como seres vivos dotados de sensibilidad. Se prevé la aplicación del régimen jurídico de los bienes en la medida en que sea compatible con su naturaleza y las disposiciones destinadas a su protección.

Este nuevo art. 333 del Código Civil incorpora que el propietario de un animal debe respetar su cualidad de ser dotado de sensibilidad, asegurando su bienestar conforme a las características de cada especie. Por otro lado, la indemnización por el sufrimiento moral sufrido en caso de que un tercero lesione gravemente a nuestro animal de compañía, es otro de los puntos que merecen ser apuntados. Otro de los artículos que se modificarían y que es digno de alusión es el art. 611, que recogería el caso de encontrarse con un animal perdido, con la obligación de restituirlo a su dueño o avisarle del hallazgo.

Por otro lado, en sede de "efectos comunes a la nulidad, separación y divorcio", el art. 90 indicaría que el convenio regulador en estos casos deberá contener el destino de los animales de compañía, teniendo en cuenta el bienestar del animal, pudiendo preverse el reparto de los tiempos de disfrute si fuere necesario. Además, en el mismo tema, se añadiría un art. 94 bis, cuyo contenido sería el siguiente: "la autoridad judicial confiará los animales de compañía a uno o ambos cónyuges, atendiendo al interés de los miembros de la familia y al bienestar del animal".

Finalmente, la modificación del art. 111 de la Ley Hipotecaria dejaría fuera del alcance de una hipoteca a los animales de compañía y en este sentido el art. 605 de la Ley de Enjuiciamiento Civil los declararía inembargables.

Bien, a pesar de que, evidentemente, esta reforma constituye progreso en la consideración que tenemos como sociedad de los animales de compañía, no deja de tener una sensación agridulce. Después de las anteriores páginas, en donde se ha podido vislumbrar una pequeña parte del calvario que sufren desde que nacen los animales, víctimas del sistema de ganadería actual, reformas de este tipo, centrando única y exclusivamente el foco en los animales de compañía, fomentan aún más la distinción entre estos y aquellos.

Abordando el tema con optimismo, quizás este sea el camino hacia un futuro esperanzador para el resto de animales.

\section{II.2.3 El maltrato animal en el Código Penal}

La reforma del Código Penal operada por la Ley Orgánica 15/2003, de 25 de noviembre, introdujo, por medio del art. 337, la pena de prisión para aquellos que maltrataren con ensañamiento e injustificadamente a animales domésticos, causándoles la muerte o provocándoles lesiones graves. Posteriormente, en 2010, se eliminó la necesidad de que exista ensañamiento y se incluyó la categoría de animales amansados (lo cual vino con la polémica de qué animales entraban dentro de esta categoría). 
Actualmente, la modificación por la Ley Orgánica 1/2015, de 30 de marzo, deja el maltrato de animales en el art. 337 y regula el abandono de éstos en un nuevo art. 337 bis. La exigencia de un maltrato injustificado deja fuera aquellas actuaciones (como las vistas durante toda esta segunda parte) que, a pesar de ser un evidente maltrato, están justificadas por su propio fin.

Asimismo, se requiere una lesión que menoscabe gravemente la salud del animal o someterlo a explotación sexual. Tras unas agravaciones de la pena cuando se hayan utilizado instrumentos peligrosos para la vida del animal, pérdida o inutilidad de un sentido, órgano o miembro principal, o que el maltrato haya tenido lugar en presencia de un menor de edad, el único caso en el que la pena puede ser mayor al año (máximo de 18 meses) es cuando se causa la muerte del animal.

Gracias a esta reforma, por fin se contempla penalmente el abandono de animales (que no viva en estado salvaje), a través del art. 337 bis, a pesar de que la pena deje bastante que desear.

\section{II.3 Normativa autonómica}

Son 17 comunidades autónomas y 17 leyes autonómicas de protección animal. A estas hay que sumarle el Reglamento de la ciudad autónoma de Ceuta para la tenencia, protección y bienestar de los animales de compañía, de 28 de abril de 2015, y el Reglamento regulador de la sanidad animal de la ciudad autónoma de Melilla, publicado el 23 de marzo de 2010.

La competencia de las comunidades autónomas en la materia y la ausencia de una ley estatal que armonice el contenido de las mismas propician que existan enormes disparidades entre ellas. A esto hay que sumarle la aplicación del Convenio Europeo sobre protección de animales de compañía, el cual va a obligar a que muchas comunidades tengan que adaptar sus leyes.

En la Región de Murcia, la Ley 6/2017, de 8 de noviembre, de protección y defensa de los animales de compañía, ha supuesto un avance respecto a la legislación anterior, de 1990. Con esta nueva ley se ha intentado acercar aún más el derecho a la concepción que la sociedad tiene respecto a los animales de compañía, lo cual se ve reflejado en alguno de los siguientes puntos, entre otros:

a) Se ha aumentado significativamente el catálogo de actuaciones prohibidas, como por ejemplo: las mutilaciones de animales por razones estéticas, la donación o venta a menores de 16 años y personas con la capacidad modificada judicialmente sin la debida autorización, dar a los animales una educación agresiva o violenta o prepararlos para peleas o mantener animales en vehículos estacionados sin la ventilación y temperatura adecuada (art. 5).

b) Una pormenorizada regulación de las condiciones de tenencia y transporte. Asimismo, se prohíbe con carácter general mantener atados a los animales de compañía en el entorno domiciliario. No obstante, se permitirá en casos puntuales, en los cuales se deberá disponer de un habitáculo, comedero y bebedero, la atadura no podrá ser nunca inferior a 3 metros y el tiempo no podrá superar las 10 horas continuadas al día (art. 7).

c) Las limitaciones sobre circulación y acceso de animales de compañía en las vías, transportes y establecimientos públicos contenidas en los artículos 8 a 10 no son 
aplicables a los perros de asistencia para personas con discapacidad y a los que son utilizados como terapia asistida en casos de violencia de género (art. 11).

d) En los establecimientos de venta de animales con escaparate, no se puede exponer animales de compañía en los mismos (art. 21.1 d.).

\section{CONCLUSIONES}

Se ha optado por que esta última parte esté dividida en tres ideas, cuya intención es facilitar la comprensión del sentido de este texto. En primer lugar, se tomará la corriente que se había venido dando a lo largo de la segunda parte como una conclusión: la tendencia de las leyes de no superar el bienestarismo impide transformar la consideración egoísta que tenemos de los animales como un medio para nuestros propios intereses, a pesar de que los tratemos más "humanamente". En segundo lugar, aparecen otras razones de peso para cambiar de rumbo: no solo es una cuestión de ética, que ya sería suficiente, sino que surge como gran perjudicado de este sistema de explotación el medio ambiente y, evidentemente, nuestra propia salud. Finalmente, se abrirá el camino a seguir a medio y largo plazo: el abolicionismo en el derecho es posible si a nivel político se toma en serio la causa animal.

\section{III.1 Por qué el bienestarismo es insuficiente}

El fundamento filosófico de toda la cuestión referida a los animales ha permitido disponer de unas herramientas como para poder ahondar en la normativa actual desde una perspectiva distinta. Abrazar la concepción de que la explotación animal supone una forma más de esclavitud, en donde perpetuamos una voluntad de dominación sobre el individuo que consideramos inferior, será difícil de alcanzar si continuamos desde una óptica bienestarista. Asimismo, como se habrá podido comprobar, la normativa vigente se rige por un corte marcadamente antropocentrista, considerando el interés del ser humano como fin último. Por ello, en muchos de los ejemplos que se han visto se entiende el bienestar animal como algo indirecto, necesario, para la salud del ser humano y la evolución del sector económico.

No obstante, más que preocuparnos por la evolución del sector económico deberíamos preocuparnos más bien por la evolución de la propia especie humana. Esta evolución pasa por interiorizar que la dominación y sometimiento del resto de animales constituye una forma más de discriminación, por el mero hecho de que pertenecen a una especie diferente y nuestras diferencias con ellos sean enormes. Empero, aunque sean evidentes nuestras diferencias, como vaticinaba Peter Singer en su libro Liberación Animal, reconocerlas no impide que se extienda el principio básico de la igualdad a los animales no humanos. Esta igualdad no significa, evidentemente, que ostentemos los mismos derechos de un sistema jurídico creado por el ser humano. ${ }^{42}$ En palabras de Corine Pelluchon, consistiría más concretamente en organizar la coexistencia entre humanos y no humanos, incluyendo los intereses de estos últimos en la definición del bien común, poniendo límites a nuestra relación con ellos para crear de esta manera una sociedad justa en la que también se vean beneficiados. ${ }^{43}$ Así, por lo tanto, habría que fijarse más bien en los aspectos en que somos semejantes, ayudando así a superar esta posición dominante y opresora.

\footnotetext{
42 SINGER, P., Liberación Animal, Madrid, Editorial Trotta, 1999, 38.

${ }^{43}$ PELLUCHON, C., Manifiesto Animalista, 68-69.
} 


\section{III.2 Los tres pilares: Ética, Medio Ambiente y Salud}

Lo que se pretende con esta idea es ver de soslayo que la cuestión de la explotación animal no solamente puede ser afrontada desde la ética, sino también desde otros enfoques. Es más, una perspectiva multidisciplinar resulta enormemente útil para reforzar aún más la necesidad de un cambio de mentalidad. Dicho esto, y según datos ofrecidos por un informe de Greenpeace $^{44}$, en España el sector ganadero emitió en 2015 más de 86 millones de toneladas de dióxido de carbono, casi el doble de lo que establece el Instituto Nacional de Estadística para el sector de la agricultura, ganadería, silvicultura y pesca juntos. Asimismo, consume anualmente 48.000 millones de metros cúbicos de agua, equivalente al consumo de los hogares españoles durante 21 años. Empero, no solamente afecta al cambio climático y al consumo del agua, sino que los cultivos para la alimentación animal requirieron en ese mismo año 18 millones de hectáreas, tanto de España como del extranjero, teniendo en cuenta la importación de soja y otros cereales.

Por lo que hace a la cuestión de la salud, en octubre de 2015 el Centro Internacional de Investigaciones sobre el Cáncer, órgano de la Organización Mundial de la Salud especializado en el cáncer, clasificó la carne roja (res, ternera, cerdo, cordero, caballo y cabra) como probablemente carcirógena para los humanos (Grupo $2^{\mathrm{a}}$, donde se encuentran los gases de combustión o esteroides) y la carne procesada como carcirógena (Grupo 1, junto al tabaco o el amianto). ${ }^{45}$

\section{III.3 Por un futuro sin utilizar animales: el abolicionismo en el derecho es posible.}

En la primera parte el abolicionismo se presentaba como la opción para construir una sociedad más justa, no solamente entre los seres humanos, sino teniendo en cuenta también el resto de especies que pueden llegar a sufrir por la interacción con los humanos. El Derecho, por lo tanto, debe determinar las reglas de convivencia para con el resto de animales, de tal forma que sea posible garantizar plenamente el respeto a sus intereses. Esto se configura como una transformación progresiva, en la que cada cambio habrá de ser razonable y oportuno, sin perder el rumbo de acabar con la explotación animal.

\section{REFERENCIAS BIBLIOGRÁFICAS}

- ABoglio, A. M., "Discurso proteccionista y opresión animal”, A.G.I.D., La cuestión animal(ista), pp. 111-148.

- Asociación de Veterinarios abolicionistas de la tauromaquia y Del MALTRATO ANIMAL: Informe matanza sin aturdimiento previo, (2017), pp. 2-3 (https://avatmaorgblog.files.wordpress.com/2017/05/informe-matanza-sin-aturdimientoprevio-6-12-2017.pdf). Fecha de acceso: 12-06-2018.

\footnotetext{
44 "La insostenible huella de la carne en España", marzo 2018, Greenpeace España. Para ver el informe completo: https://es.greenpeace.org/es/wp-content/uploads/sites/3/2018/03/INFORME-CARNEv5.pdf

${ }^{45}$ Estudio completo del CIIC: https://monographs.iarc.fr/wp-content/uploads/2018/06/mono114.pdf. Comunicado de prensa del CIIC: http://www.who.int/mediacentre/news/releases/2015/cancer-red-meat/es/.
} 
- Balcombe, J., "Cognitive evidence of fish sentience", Animal Sentience Journal, 2016. 008: Balcombe Commentary on Key on Fish Pain, pp. 1-2 (https://animalstudiesrepository.org/cgi/viewcontent.cgi?referer=\&httpsredir=1\&article $=1059 \&$ context=animsent). Fecha de acceso: 13-07-2018.

- Broom, D. M., "Fish brains behaviour indicates capacity for feeling pain", Animal Sentience Journal, 2016.010: Broom Commentary on Key on Fish Pain, pp. 1-3 (https://animalstudiesrepository.org/cgi/viewcontent.cgi?referer=\&httpsredir=1\&article $=1031 \&$ context=animsent $)$. Fecha de acceso: $13-07-2018$.

- Brown, C., "Fish pain: An inconvenient truth", Animal Sentience Journal, 2016, pp. 12:

(https://animalstudiesrepository.org/cgi/viewcontent.cgi?referer=\&httpsredir=1\&article 1069\&context=animsent). Fecha de acceso: 13-07-2018.

- Centro internacional De Investigaciones Sobre El CÁncer: Read Meat and processed meat. Volume 114. El informe, en inglés, en la siguiente página web: https://monographs.iarc.fr/wp-content/uploads/2018/06/mono114.pdf. Fecha de acceso: 08-07-2018.

- Comunicado de prensa: http://www.who.int/mediacentre/news/releases/2015/cancerred-meat/es/. Fecha de acceso: 08-07-2018.

- COMISIÓn EUROPEA: Informe al Parlamento Europeo y al Consejo relativo a los distintos métodos de aturdimiento para las aves de corral (2013). Puede verse el informe completo aquí: https://eur-lex.europa.eu/resource.html?uri=cellar:4a78327176c6-11e3-b889-01aa75ed71a1.0008.01/DOC_1\&format=PDF. Fecha de acceso: 0107-2018.

- Crespo Carrillo, C. A., "Liberación animal desde una bioética no especista", A.G.I.D., La cuestión animal(ista), Bogotá, Ediciones desde abajo, (2016), pp. 359-368.

- Efe Noticias: "Extremadura sacrifica por el rito halal para vender carne a los emiratos": https://www.efe.com/efe/espana/sociedad/extremadura-sacrifica-por-el-ritohalal-para-vender-carne-a-los-emiratos/10004-3577063. Fecha de acceso: 07-07-2018.

- EISNITZ, G. A., Slaughterhouse, New York, Prometheus Books, 1997.

- Ética Animal, "Teorías éticas y animales no humanos. Se puede encontrar aquí: http://www.animal-ethics.org/etica-animales-seccion/teorias-eticas-animales-nohumanos/. Fecha de acceso: 20-06-2018.

- EUROPA PRESS: "Aparecen un centenar de conejos muertos sin comida ni agua en una nave en Suances" (http://www.europapress.es/cantabria/noticia-aparecen-centenarconejos-muertos-comida-agua-nave-suances-20170512110845.html). Fecha de acceso: 02-07-2018.

- Eurostat (Oficina de Estadística de la Comisión Europea). Los datos estadísticos pueden verse en este link: http://ec.europa.eu/eurostat/web/agriculture/data/database.

- FARIA, C., "Equality, Priority and Nonhuman Animals", No 14, Dilemata, (2014), pp. 225-236. 
- Gallego Amores, D., "El reconocimiento de derechos para los animales no humanos como requisito de una sociedad justa", El mejoramiento humano: avances, investigaciones y reflexiones éticas y políticas, Granada, Ed. Comares, (2015), pp. 778787.

- GREENPEACE ESPAÑA: Informe "La insostenible huella de la carne en España" (2018). El informe completo puede encontrarse en el siguiente enlace: https://es.greenpeace.org/es/wp-content/uploads/sites/3/2018/03/INFORME-

CARNEv5.pdf. Fecha de acceso: 06-07-2018.

- Guerra Palmero, M. J., "Derechos de los animales y justicia interespecífica", Laguna, (2000), pp. 375-379.

- Horta, O., Un paso adelante en defensa de los animales, Madrid, Plaza y Valdés Editores, (2017), pp. 20-21.

- Horta, O., "El cuestionamiento del antropocentrismo: distintos enfoques normativos", Revista de Bioética y Derecho, № 16, (2009), pp. 36-39.

- HoRTA, O., "Igualitarismo, igualación a la baja, antropocentrismo y valor de la vida, Revista de Filosofía, (2010), № 1, pp. 133-152.

- IgUALDAD ANIMAL: "Igualdad animal revela sadismo y brutalidad ocultos en la granja de cerdos de El Escobar" (http://www.igualdadanimal.org/noticias/6348/igualdadanimal-revela-sadismo-y-brutalidad-ocultos-en-la-granja-de-cerdos-de-el-escobar).

Fecha de acceso: 12-07-2018.

- La OPINIÓN DE MURCia: "Descubren un matadero de conejos clandestino en el sótano de un restaurante de Murcia". La noticia, en el siguiente enlace: https://www.laopiniondemurcia.es/murcia/2017/07/06/descubren-matadero-conejosclandestino-sotano/843117.html. Fecha de acceso: 02-07-2018.

- LaURen StefFen, J. Y Klanovicz De ARAúJo, C., "Animal ethics theories: the current debate", dA. Derecho Animal: Forum of Animal Law Studies, (2015), Vol. 6, № 3.

- Leyton Donoso, F., "Bioética frente a los derechos animales: tensión en las fronteras de la filosofía moral", Tesis doctoral dirigida por Óscar Horta Álvarez y Norbert Bilbeny, Universitat de Barcelona, (2015), pp. 134.

- Ministerio de Agricultura, Pesca y Alimentación - Ministerio para la TRANSICIÓN ECOLÓGICA: Estadísticas de sacrificio del ganado (http://www.mapama.gob.es/es/estadistica/temas/estadisticasagrarias/ganaderia/encuestas-sacrificio-ganado/). Fecha de acceso: 01-07-2018.

- Documento sobre la gestión de las explotaciones porcinas para evitar la caudofagia (2017): $\quad$ http://www.mapama.gob.es/es/ganaderia/temas/produccion-y-mercadosganaderos/20171031documentosobregestiondelasexplotacionesparalaprevenciondelrabo teo tcm30-441875.pdf. Fecha de acceso 12-06-2018.

- Guía de buenas prácticas de higiene en explotaciones cunícolas(2011): http://www.mapama.gob.es/es/ganaderia/publicaciones/CBBPP_CUNICULTURA2011-WEB_tcm30-105270.PDF. Fecha de acceso: 02-07-2018. 
- Pelluchon, C., Manifiesto animalista, Barcelona, Penguin Random House Grupo Editorial, (2018), pp. 68-69, 91-92 y 129 (título original: Manifeste animaliste, París, Alma Éditeur, (2017).

- PÉRez Monguió, J. M., "Marco jurídico de la protección animal en España desde 1929 hasta 2015. El lento y firme trote del mastín", Revista Aranzadi de derecho ambiental, (2015), pp. 32 y 285-333.

- PÉrez Monguió, J. M., “Antecedentes históricos jurídicos-administrativos de la protección animal en España”, Animalia: revista profesional de los animales de compañía, (2009), pp. 216 y 52-55.

- Pérez Monguió, J.M., Reseña de Animales de compañía. Régimen jurídico en el derecho administrativo, ROCA FERNÁNDEZ-CASTANYS, M.L., Barcelona, Editorial Bosch, (2005).

- Pettorali, M., "Una crítica a la profesión veterinaria desde una perspectiva antiespecista”, Revista de bioética y derecho, №37, (2016), pp. 121-131.

- PúBliCo: "El tirón de la carne halal dispara el sacrificio de animales sin aturdimiento en España": $\quad$ http://www.publico.es/sociedad/maltrato-animal-tiron-carne-halal-disparasacrificio-animales-aturdimiento-espana.html. Fecha de acceso: 07-07-2018.

- Ryder, R. D., "Speciesism Again: the original leaflet”, Critical Society, (2010), pp. 1-2.

- Singer, P., Liberación Animal, Madrid, Editorial Trotta, (1999), pp. 38.

- Singer, P., "Ética más allá de los límites de la especie", Teorema: Revista internacional de filosofía, (1999), $\mathrm{N}^{\mathrm{o}} 3$, pp. 5-16.

- Torres Aldave, M., "La teoría de los derechos de los animales de Tom Regan", biTARTE, (2009), pp. 5-24.

- Torres Aldave, M., "Capacidades y derechos de los animales: argumentos a favor de la teoría de M.C. Nussbaum", Nº1, Dilemata, (2009), pp. 33-47.

- VEGAN SOCIETY: https://www.vegansociety.com/go-vegan/definition-veganism. Fecha de acceso: 05-05-2018. 